\title{
Novel and stability indicating HPLC method for Ezetimibe, Rosuvastatin, Atorvastatin in tablets form
}

Authors \& Affiliation:

\section{Manchuru Vanaja* Yeragodala}

Narendra Reddy and J.Sreeramulu

Department of Chemistry,

Sri Krishnadevaraya University, Anantapur, AP, India

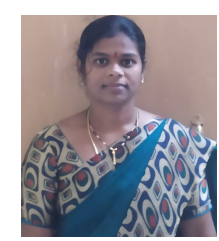

\section{Corresponding Author:}

Manchuru Vanaja
(C) 2020.The Authors. Published under

Caribbean Journal of Science and Technology

\begin{abstract}
:
Rugged and robust HPLC method was developed for assay determination of Ezetimibe, Rosuvastatin, and Atorvastatin in tablet dosage form. These three drugs used to treat the human body bad and good cholesterol management in blood. Ezetimibe and rosuvastatin are available in the market in tablets dosage form; Ezetimibe and atorvastatin combinations also available in the market. $0.05 \mathrm{M} \mathrm{KH}_{2} \mathrm{PO}_{4}$ buffer was used as mobile phase $\mathrm{A}$ and acetonitrile is used as mobile phase B. Gradient program was used as eluent, $30 \%$ of mobile phase $\mathrm{B}$ at $0 \mathrm{~min} ; 30 \%$ at $5 \mathrm{~min} ; 42 \%$ at $8 \mathrm{~min} ; 40 \%$ at $12 \mathrm{~min}$; and $30 \%$ at $16 \mathrm{~min}$ and $30 \%$ at $20 \mathrm{~min}$. Agilent make Zorbax SB C18 150*4.6 $\mathrm{mm}, 5 \mu \mathrm{HPLC}$ column was used. $20 \mu \mathrm{L}$ injection volume, 20 min runtime, $1.0 \mathrm{ml} / \mathrm{min}$ flow rate, $230 \mathrm{~nm}$ and $50^{\circ} \mathrm{C}$ column oven temperature were applied for analysis. Mobile phase A and B were mixed in the ratio of 50:50 $\mathrm{v} / \mathrm{v}$ and used as diluent. All three analytes were eluted with high resolution and the retention time of ezetimibe $15.3 \mathrm{~min}$, rosuvastatin $9.0 \mathrm{~min}$ and atorvastatin $17.1 \mathrm{~min}$. method validation was performed as per ICH quality guidance. Results were achieved with accuracy and precision. Hence, the developed and validated method was applicable for routine drug product manufacturing quality evaluation.
\end{abstract}

Keywords: Ezetimibe, Rosuvastatin, Atorvastatin, HPLC,

Method development, Method validation

ISSN 0799-3757 


\section{Introduction:}

Ezetimibe controls the absorption of cholesterol and decreasing the release of intestinal cholesterol to the liver. Ezetimibe (EZE) is [(3R,4S)-1-(4-fluorophenyl)-3-[(3S)-3-(4fluorophenyl)-3-hydroxypropyl]-4-(4-hydroxyphenyl)- 2-azetidinone]. It manages the cholesterol absorption (primary hypercholesterolemia). It inhibits the absorption of biliary and dietary cholesterol from small intestine without influencing absorption of fat soluble vitamins, triglycerides and bile acids. ${ }^{[1-2]}$ After oral administration, Ezetimibe is metabolized into its glucuronide in the liver and small intestine, which is also active in prevention of absorption of cholesterol. Ezetimibe does not have significant pharmacokinetic interactions with other lipid lowering drugs. ${ }^{[3-4]}$

Atorvastatin is used to treat anti-hyperlipidemic (lipid lowering) class of drug which reduces the amount of fatty or lipid substances such as cholesterol and triglycerides from the body. Chemical name of atorvastatin is 7-[2-(4-fluorophenyl)-3-phenyl-4-(phenylcarbamoyl)-5-(propan-2-yl)1H-pyrrol-1-yl]-3,5-dihydroxyheptanoate, calcium salt (2:1) trihydrate. Figure-1 represented the chemical structures of ezetimibe, Atorvastatin, rosuvastatin.

Rosuvastatin calcium is chemically, bis[(E)-7[4-(4-fluorophenyl)-6-isopropyl-2-[methyl (methylsulphonyl)amino]pyrimidin-5-yl](3R,5S)-3,5-dihydroxyhept-6-enoic acid] calcium salt). It belongs to a statins family, which are employed to lower hypercholesterolemia and related conditions and to prevent cardiovascular diseases. It increases the number of hepatic low density lipoprotein receptors involved in the catabolism of LDL and also inhibits hepatic synthesis of very low density lipoprotein. ${ }^{[5-8]}$

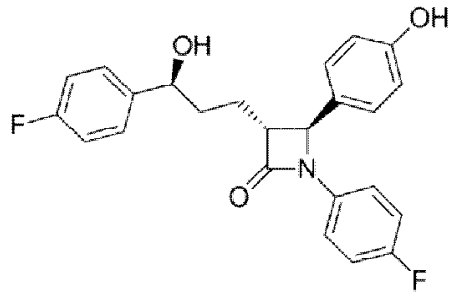

Ezetimibe

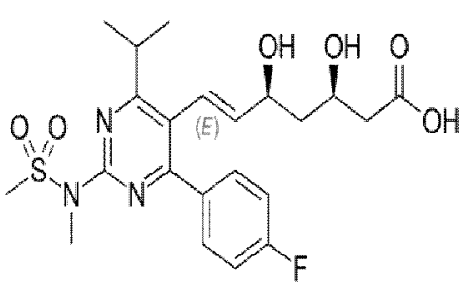

Rosuvastatin

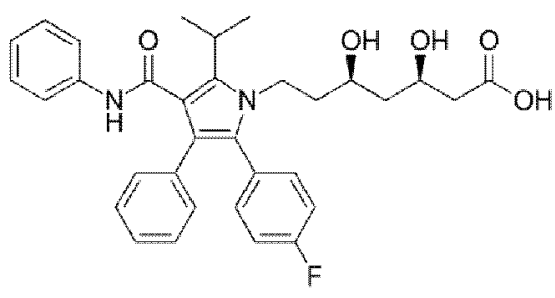

Atorvastatin

Figure-1: Chemical structure of Ezetimibe, Atorvastatin and Rosuvastatin

Literature survey was performed for these three analytes determination for single HPLC method but there is no single method was reported. Few methods were reported for ezetimibe and

rosuvastatin determination by using HPLC, UV spectrophotometric methods. ${ }^{[9-11]}$ Ezetimibe and atorvastatin combination product also have very few reported methods. ${ }^{[12-17]}$

The main objective of this research work was to develop an single, accurate and rugged HPLC method to determine ezetimibe, rosuvastatin and atorvastatin in pharmaceutical drug products. 


\section{Materials and Method:}

\section{Chemicals and reagents:}

HPLC standard acetonitrile and methanol were purchased from Qualigens fine chemicals, Mumbai, India. Distilled, $0.45 \mu \mathrm{m}$ filtered water used for HPLC analysis. Sd. fine chem analytical grade $\mathrm{KH}_{2} \mathrm{PO}_{4}$ salt was purchased and used for the preparation of mobile phase. Milli$\mathrm{Q}$ water was used for the analysis.

\section{Chromatographic conditions:}

Agilent make HPLC systems and carry win UV spectrophotometer were used for this research work. Zorbax SB C18, 150×4.6 mm, $5 \mu \mathrm{m}$ HPLC column was used (agilent make). $1.0 \mathrm{ml} / \mathrm{min}$ flow rate, $420 \mu \mathrm{L}$ injection volume and $50^{\circ} \mathrm{C}$ column oven temperature were applied. UV absorbance was measure at $230 \mathrm{~nm}$.

\section{Mobile phase A:}

$6.8 \mathrm{~g}$ of $\mathrm{KH}_{2} \mathrm{PO}_{4}$ buffer salt was weighed accurately and transferred in to $1000 \mathrm{ml}$ beaker, mixed well. Sonication was performed to dissolve the contents. Resulting solution was degassed with and filtered through $0.45 \mu \mathrm{m}$ Millipore membrane filter and sonicated.

\section{Mobile phase B:}

HPLC grade acetonitrile was used as mobile phase B, degassed through $0.45 \mu \mathrm{m}$. Millipore membrane filter and sonicated for few minutes.

\section{Diluent:}

Mobile phase A and B were mixed in the ratio of 50:50 v/v and degassed through $0.45 \mu$ filter.

\section{Standard Solution:}

$40 \mathrm{mg}$ of each standard material such as rosuvastatin, ezetimibe and Atorvastatin was weighed accurately and transferred in to a $100 \mathrm{~mL}$ volumetric flask and dissolved in $50 \mathrm{~mL}$ of diluent and sonicated to dissolve the contents. Further, volume was filled with diluent solution. From the above stock solution $5 \mathrm{~mL}$ aliquot was pipetted in to a $50 \mathrm{~mL}$ volumetric flask and dissolved in the solvent and made up to the mark with the diluent.

\section{Ezetimibe and Atorvastatin test sample solution:}

The contents of twenty ezetimibe and Atorvastatin tablets were taken and finely powdered. A mass equivalent to $56 \mathrm{mg}$ of each ezetimibe and Atorvastatin was transferred to a $100 \mathrm{~mL}$ volumetric flask and dissolved in $50 \mathrm{~mL}$ of the diluent. The solution was kept for sonication for $15 \mathrm{~min}$. The solution was made up to the mark with the diluent and filtered through a $0.45 \mu$ membrane filter. $5 \mathrm{~mL}$ aliquot of the above solution was transferred to a $50 \mathrm{~mL}$ volumetric flask and diluted to the mark with diluent.

\section{Ezetimibe and rosuvastatin test sample solution:}

The contents of twenty ezetimibe and rosuvastatin tablets were taken and finely powdered. A mass equivalent to $56 \mathrm{mg}$ of each ezetimibe and rosuvastatin was transferred to a $100 \mathrm{~mL}$ volumetric flask and dissolved in $50 \mathrm{~mL}$ of the diluent. The solution was kept for sonication for $15 \mathrm{~min}$. The solution was made up to the mark with the diluent and filtered through a $0.45 \mu$ membrane filter. $5 \mathrm{~mL}$ aliquot of the above solution was transferred to a $50 \mathrm{~mL}$ volumetric flask and diluted to the mark with diluent. 


\section{Assay Calculation:}

$\%$ of Assay=

Ta X Tw X 5 X 100 X 50 X Tweight X Spotency

$$
\text { Sa } 100 \text { X } 50 \text { X Sw X } 5 \text { X Label claim X } 100 \quad \text { x } 100
$$

$\mathrm{Ta}=$ Peak area in test solution

$\mathrm{Sa}=$ Peak area in standard solution

$\mathrm{Tw}=$ Sample weight used for test solution preparation

$\mathrm{Sw}=$ Standard weight used for standard solution preparation

Tweight $=$ Tablets average weight

Label claim= drug content in one tablet

Spotency $=$ Standard material potency

\section{Results and Discussion:}

\section{Method Optimization:}

Ezetimibe, Atorvastatin, rosuvastatin standard materials are available in solid stable form and can be stored at room temperature. Solubility of three ingredients was evaluated with different solvents like different $\mathrm{pH}$ value buffers, acetonitrile and methanol. Solubility study results shown that, all the three components have solubility with mixture of buffer, methanol and acetonitrile. Further UV spectral studies were performed by using Agilent makes carry $60 \mathrm{UV} / \mathrm{Visible}$ spectrophotometer. Three ingredients were prepared with $2 \mathrm{ppm}$ concentration to perform the UV spectral analysis. UV spectrum was scanned from 200 to $400 \mathrm{~nm}$. Figure-2 to 4 represented the UV spectrum of ezetimibe, Atorvastatin and rosuvastatin. Based on the UV spectrum results we have selected $230 \mathrm{~nm}$ to measure the analytes.

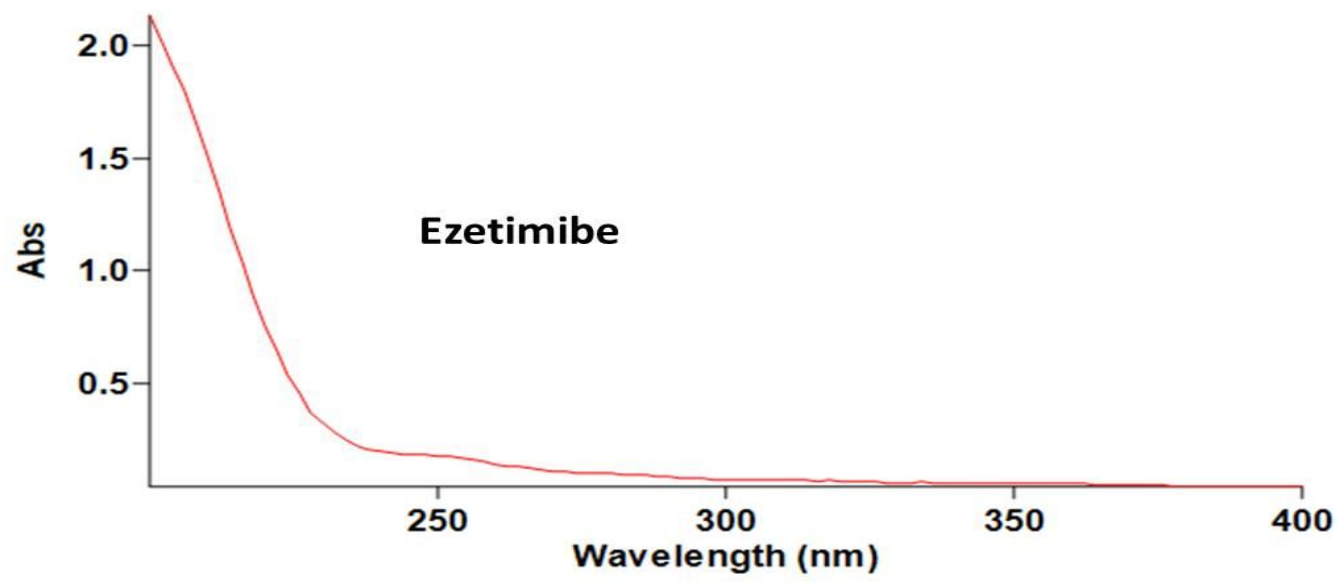

Figure-2: Ezetimibe UV spectrum 


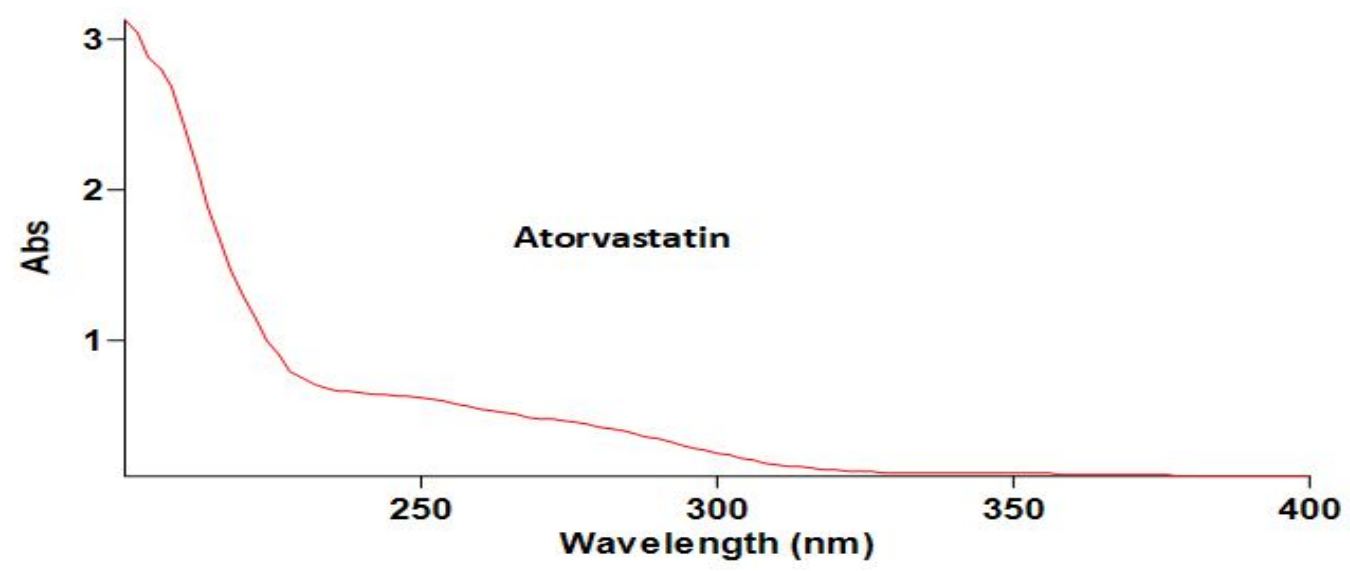

Figure-3: Atorvastatin UV spectrum

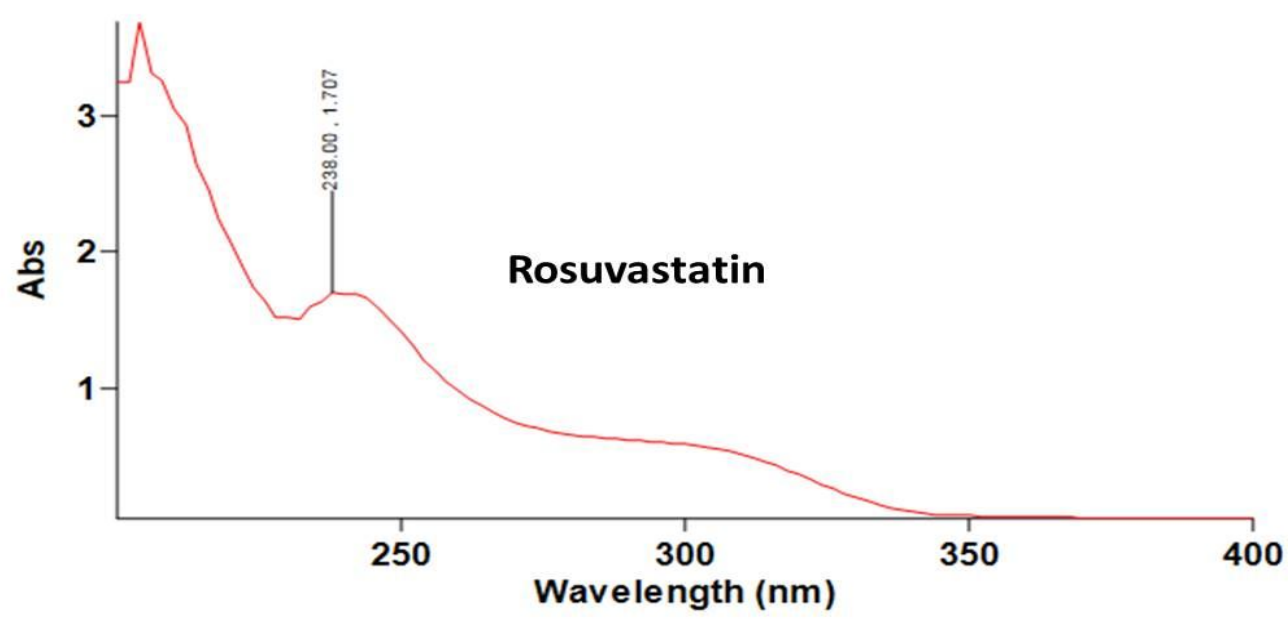

Figure-4: Rosuvastatin UV spectrum

\section{Method development experiment-1:}

\section{Conditions:}

Buffer: $0.5 \mathrm{ml}$ orthophosphoric acid and $0.5 \mathrm{ml}$ tri-ethyl amine transferred in to $1000 \mathrm{~mL}$ of water and mixed well to dissolve. Adjusted the $\mathrm{pH}$ value to 3.5 with tri-ethyl amine and filtered the solution through $0.45 \mu \mathrm{m}$ membrane filter and degassed. Mobile Phase A: Buffer; Mobile Phase B: Analytical grade acetonitrile. Isocratic elution: Mobile phase A: Mobile phase B 55:45 v/v, Column: Intertsil C8, 250 x $4.6 \mathrm{~mm}, 5 \mu \mathrm{m}$; Flow rate: $1.0 \mathrm{~mL} / \mathrm{min}$ Column Temperature: Ambient; Volume of Injection: 20 $\mu \mathrm{L}$; Wave Length: $230 \mathrm{~nm}$; Run Time: $35 \mathrm{~min}$. Diluent: Mixed $500 \mathrm{~mL}$ of water and $500 \mathrm{~mL}$ of Acetonitrile in the ratio of 50:50\% v/v and degassed. Preparation of Standard Solution: Individual sample solutions were prepared with $250 \mathrm{ppm}$ concentration with diluent solution. 


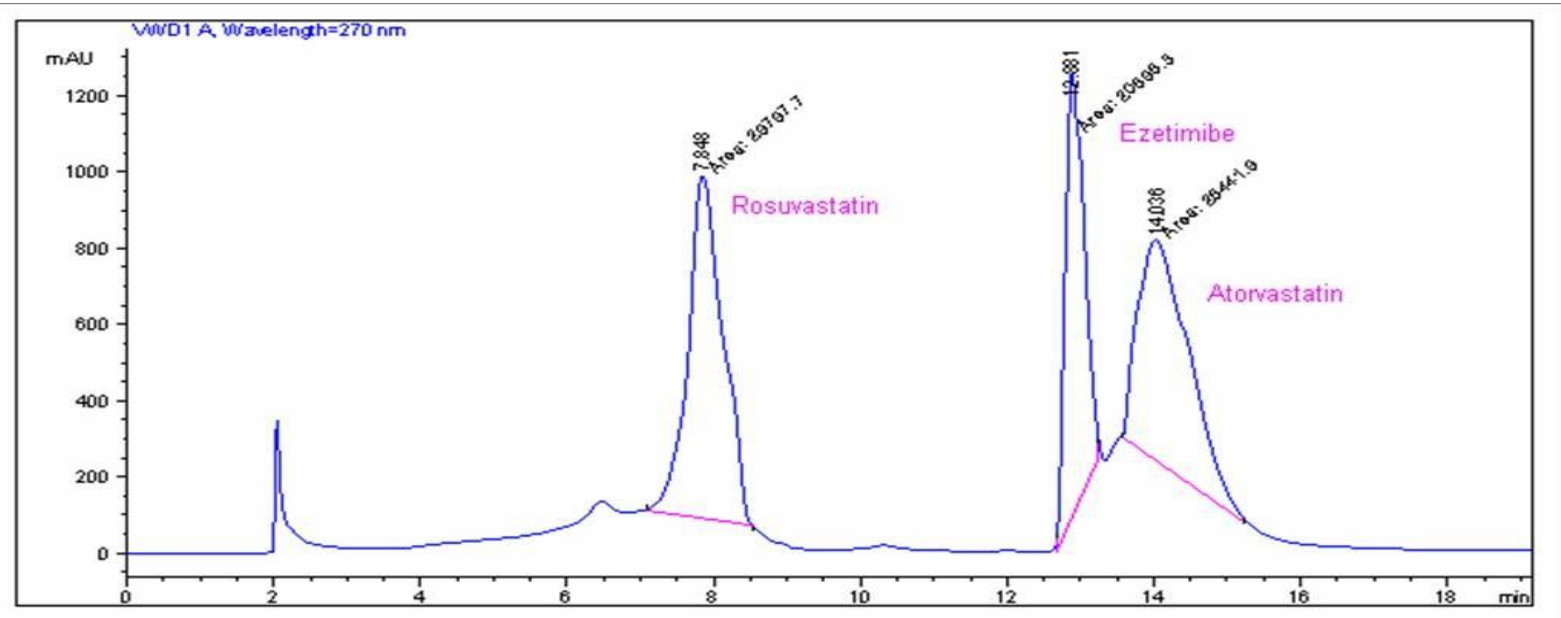

Figure-5: Method development trial-1 chromatogram

Observation: Three standard materials were eluted (rosuvastatin $7.8 \mathrm{~min}$; ezetimibe $12 \mathrm{~min}$ and atorvastatin $14 \mathrm{~min}$ ) at but Atorvastatin and ezetimibe were eluted closely. Further experiments shall be carried out with salt buffer to optimize retention time and peak shape. Figure-5 represented the method development trail chromatogram.

\section{Method development experiment-2:}

\section{Conditions:}

Buffer: $0.7 \mathrm{~g}$ of ammonium acetate salt was weighed accurately and transferred in to one liter milli-Q water and mixed well to dissolve. Adjusted the $\mathrm{pH}$ value to 3.0 with acetic acid and filtered the solution through $0.45 \mu \mathrm{m}$ membrane filter and degassed. Mobile Phase A: Buffer; Mobile Phase B: Analytical grade acetonitrile; elution: Mobile phase A: Mobile phase B 60:40 v/v; Column: Intertsil C8, 250 x 4.6

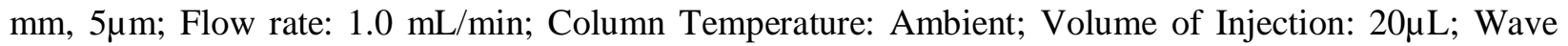
Length: $230 \mathrm{~nm}$; Run Time: $35 \mathrm{~min}$; Preparation of diluent: $500 \mathrm{~mL}$ of water and $500 \mathrm{~mL}$ of Acetonitrile were mixed and degassed. Standard Solution: Individual sample solutions were prepared with $250 \mathrm{ppm}$ concentration with diluent solution.

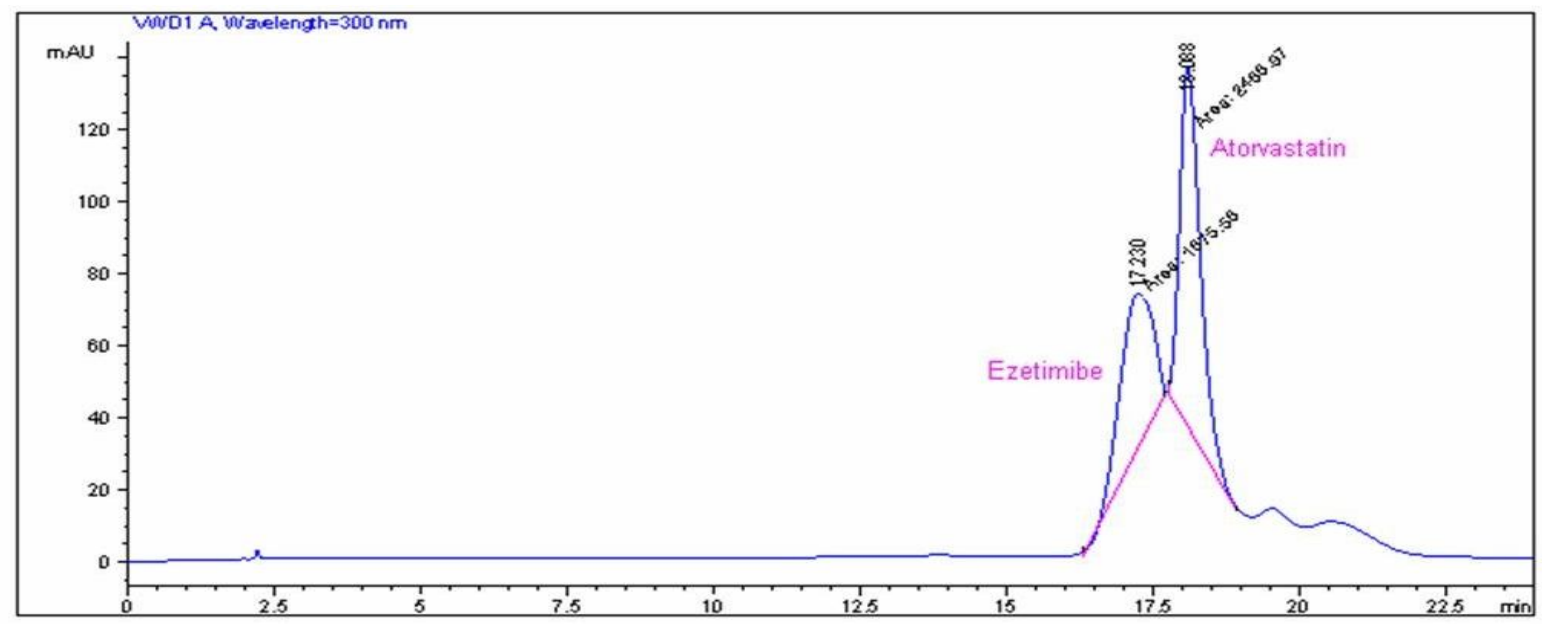

Figure-6: Method development trial-2 chromatogram 
Observation: ezetimibe and atorvastatin were co-eluted. Further experiments shall be carried out by changing the buffer salt to achieve good peak shape and different retention time for each analyte. Figure-6 represented the method development trial chromatogram.

\section{Method development experiment-3:}

Buffer solution: $3.4 \mathrm{~g}$ of $\mathrm{KH}_{2} \mathrm{PO}_{4}$ salt was weighed accurately and transferred in to $1000 \mathrm{~mL}$ of water and mixed well to dissolve. Filtered the solution through $0.45 \mu \mathrm{m}$ membrane filter and degassed. Mobile Phase A: Buffer; Mobile Phase B: Analytical grade acetonitrile. Gradient program was applied to separate the ezetimibe and atorvastatin.

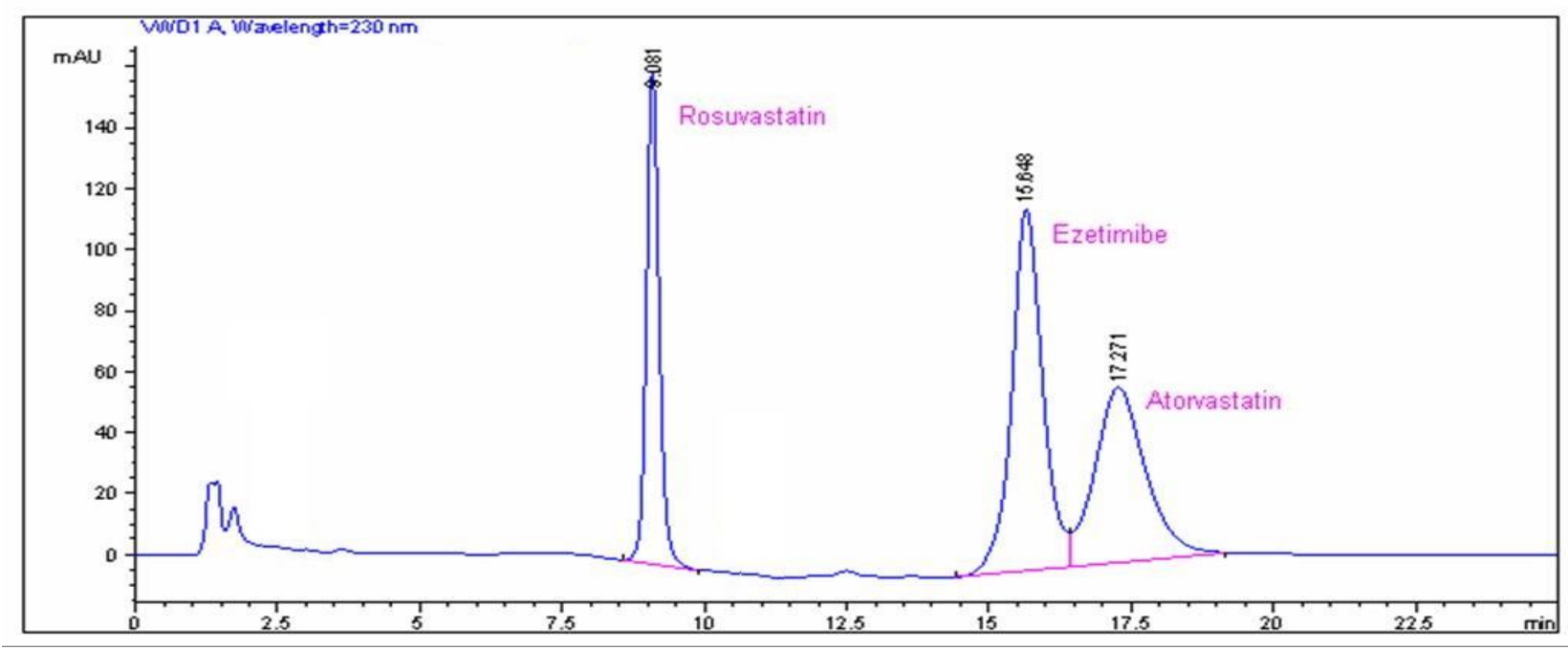

Figure-7: Method development trial-3 chromatogram

Observation: Three standard materials were eluted but resolution between ezetimibe and atorvastatin was low. Figure-7 represented the method development trial chromatogram.

\section{Method development experiment-4:}

Buffer solution: $6.8 \mathrm{~g}$ of $\mathrm{KH}_{2} \mathrm{PO}_{4}$ salt was weighed accurately and transferred in to $1000 \mathrm{~mL}$ of water and mixed well to dissolve. Filtered the solution through $0.45 \mu \mathrm{m}$ membrane filter and degassed. Mobile Phase A: Buffer and B: acetonitrile; Gradient elution: mobile phase B $27 \%$ at 0 $\mathrm{min} ; 32 \%$ at $4 \mathrm{~min} ; 45 \%$ at $8 \mathrm{~min} ; 58 \%$ at $12 \mathrm{~min} ; 27 \%$ at $16 \mathrm{~min}$ and $27 \%$ at $20 \mathrm{~min}$. other chromatographic conditions were applied as like development trial 3. 


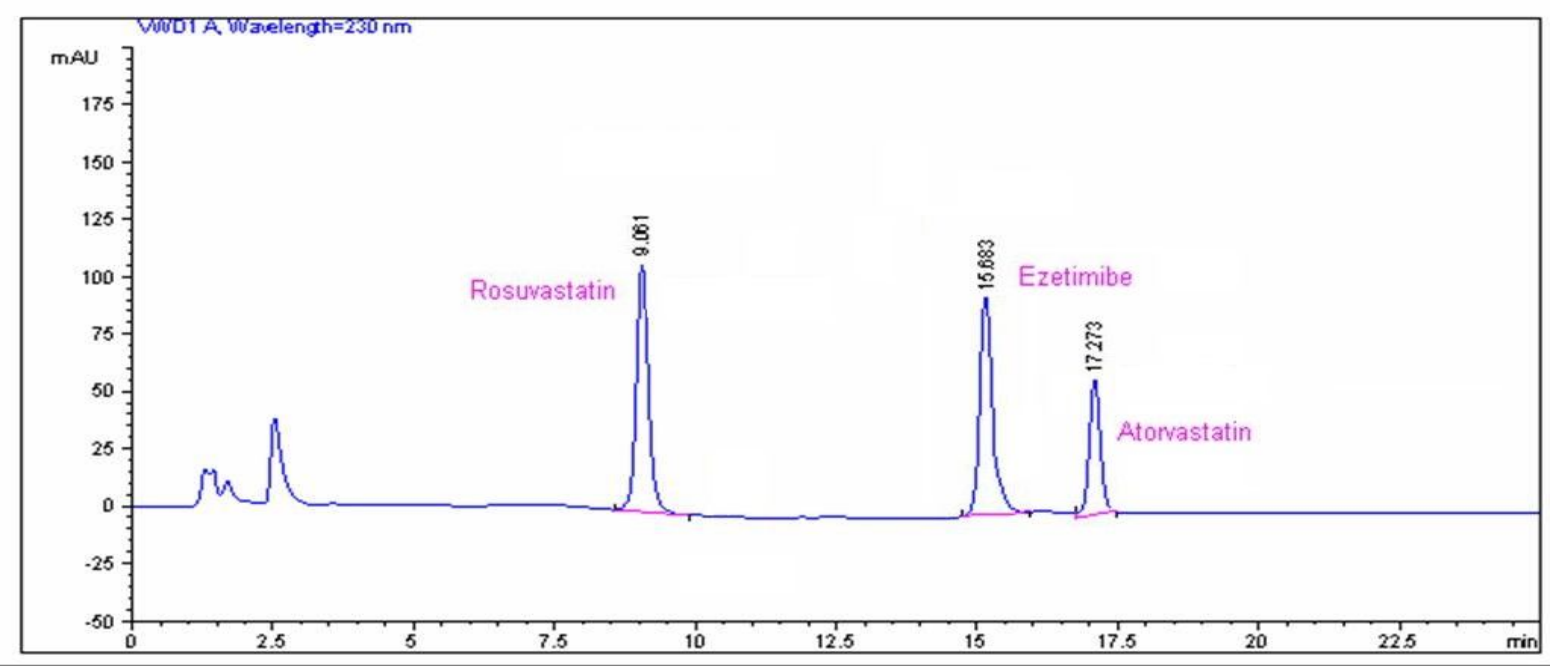

Figure-8: Method development trial-4 chromatogram

Observation: Three analytes were eluted with good peak shape. Hence, this optimized method has been considered as final method. Further, method validation can be performed. Figure- 8 represented the mixed sample chromatogram.

\section{Method validation:}

Method validation was performed as per ICH (international council for harmonization of technical requirements for pharmaceutical for human use), USFDA guidance. All parameters such as precision, linearity, specificity, accuracy, ruggedness, robustness were performed. Method validation results are meeting the acceptable limits which are specified in the guidance documents.

\section{Specificity:}

Specificity was performed to check the interference from the diluent, placebo and stress study conditions. Acidic, base, peroxide, thermal, photolytic and water stress conditions were applied on drug product. Ezetimibe and rosuvastatin test samples and ezetimibe and atorvastatin samples were stressed separately. Freshly prepared stress samples were injected into the HPLC. Stress studies results were tabulated in table 1 and 2. Figure 9 to 20 were represented the force degradation studies chromatograms. Stress study conditions were listed below,

\section{Ezetimibe and Rosuvastatin tablets Stress study conditions:}

- Acid Hydrolysis $\quad: 0.5 \mathrm{~N} \mathrm{HCl}$ at $55^{\circ} \mathrm{C}$ for 10 hours

- Base Hydrolysis : $1 \mathrm{~N} \mathrm{NaOH}$ at $55^{\circ} \mathrm{C}$ for 15 hours

- Oxidation $\left(10 \% \mathrm{H}_{2} \mathrm{O}_{2}\right)$ : at $30{ }^{\circ} \mathrm{C}$ for 6 hours

- Photolytic : UV-light (200 watts $\mathrm{hr} / \mathrm{m}^{2}$ )

- Heat : at $55^{\circ} \mathrm{C}$ for 18 hours

- Water Hydrolysis : at $55^{\circ} \mathrm{C}$ for 10 hours 
Ezetimibe and Atorvastatin tablets Stress study conditions:

- Acid Hydrolysis $\quad: 0.5 \mathrm{~N} \mathrm{HCl}$ at $55^{\circ} \mathrm{C}$ for 12 hours

- Base Hydrolysis : $1 \mathrm{~N} \mathrm{NaOH}$ at $55^{\circ} \mathrm{C}$ for 6 hours

- Oxidation $\left(10 \% \mathrm{H}_{2} \mathrm{O}_{2}\right)$ : at $30{ }^{\circ} \mathrm{C}$ for 12 hours

- Photolytic : UV-light (200 watts $\mathrm{hr} / \mathrm{m}^{2}$ )

- Heat : at $55^{\circ} \mathrm{C}$ for 12 hours

- Water Hydrolysis: at $55^{\circ} \mathrm{C}$ for 10 hours

Table-1: Stress study results.

\begin{tabular}{|l|l|l|l|l|l|l|}
\hline \multirow{2}{*}{ Active Name } & \multicolumn{1}{l}{ Torce degradation \% assay results } \\
\cline { 2 - 7 } & Acid & Base & Peroxide & UV & Thermal & Water \\
\hline Ezetimibe and rosuvastatin tablets \\
\hline Ezetimibe & 91.8 & 92.9 & 93.6 & 92.8 & 91.8 & 94.8 \\
\hline Rosuvastatin & 92.6 & 92.1 & 92.8 & 92.1 & 93.0 & 93.8 \\
\hline Ezetimibe and atorvastatin tablets \\
\hline Ezetimibe & 90.2 & 92.6 & 92.3 & 95.1 & 92.0 & 94.0 \\
\hline Atorvastatin & 91.1 & 93.5 & 93.9 & 92.6 & 93.4 & 94.9 \\
\hline
\end{tabular}

Table-2: Stress study unknown peaks data

\begin{tabular}{|l|l|l|l|l|l|l|}
\hline \multirow{2}{*}{ RT } & \multicolumn{6}{|l}{ Force degradation \% area } \\
\cline { 2 - 7 } & Acid & Base & Peroxide & UV & Thermal & Water \\
\hline Ezetimibe and rosuvastatin tablets & 2.4 & ND & ND & 1.9 & 2.9 \\
\hline 2.9 & 2.1 & 1.9 & 2.3 & 2.7 & 2.1 & 2.1 \\
\hline 6.7 & 2.0 & ND & 1.5 & 1.6 & 1.6 & 1.4 \\
\hline 21.0 & ND & \multicolumn{7}{|l|}{} \\
\hline Ezetimibe and atorvastatin tablets & 2.1 & ND & ND & ND & ND \\
\hline 2.9 & 2.9 & 1.0 & 2.4 & 1.4 & ND & ND \\
\hline 6.7 & 1.2 & ND & 1.6 & 0.9 & 1.1 & 1.0 \\
\hline 21.0 & 1.2 & & & & \\
\hline
\end{tabular}

$* \mathrm{ND}=$ Not Detected 


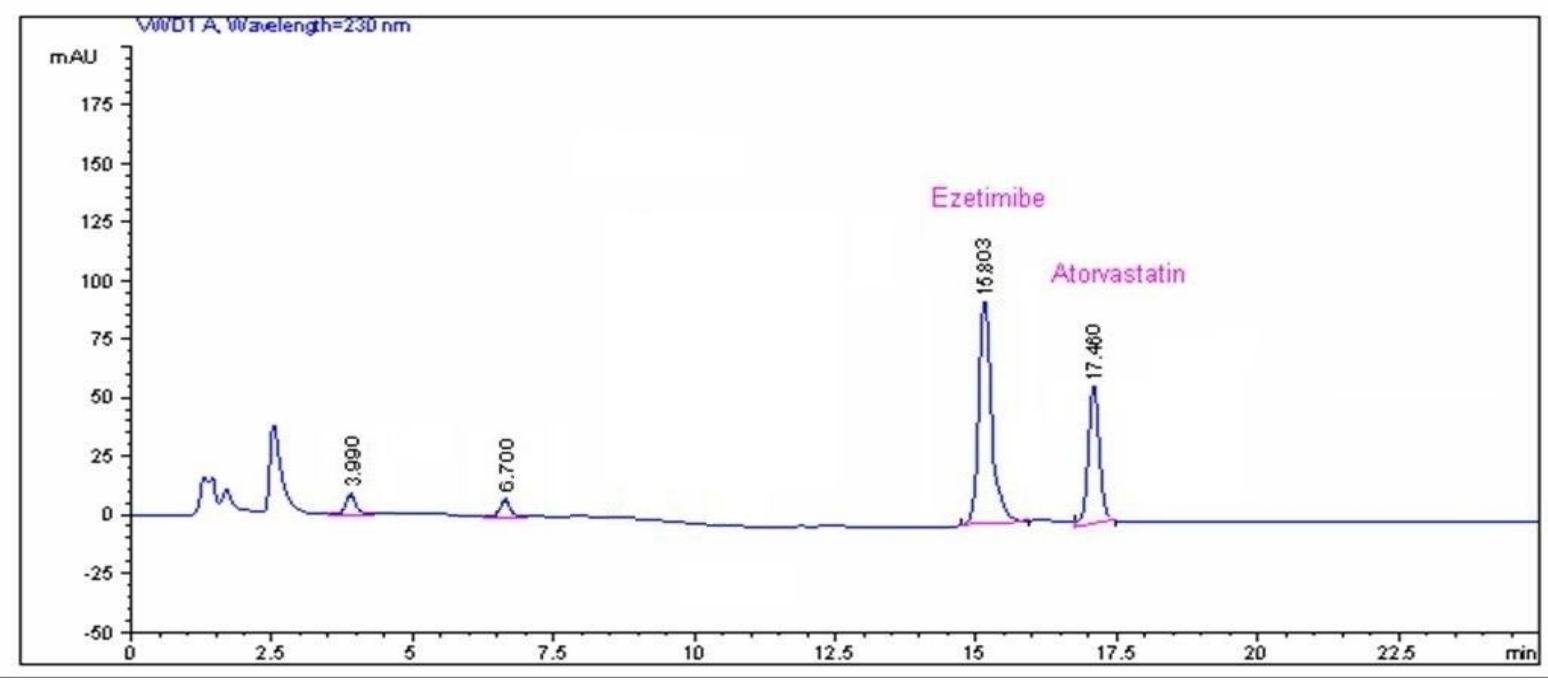

Figure-9: Ezetimibe and Atorvastatin acid degradation chromatogram

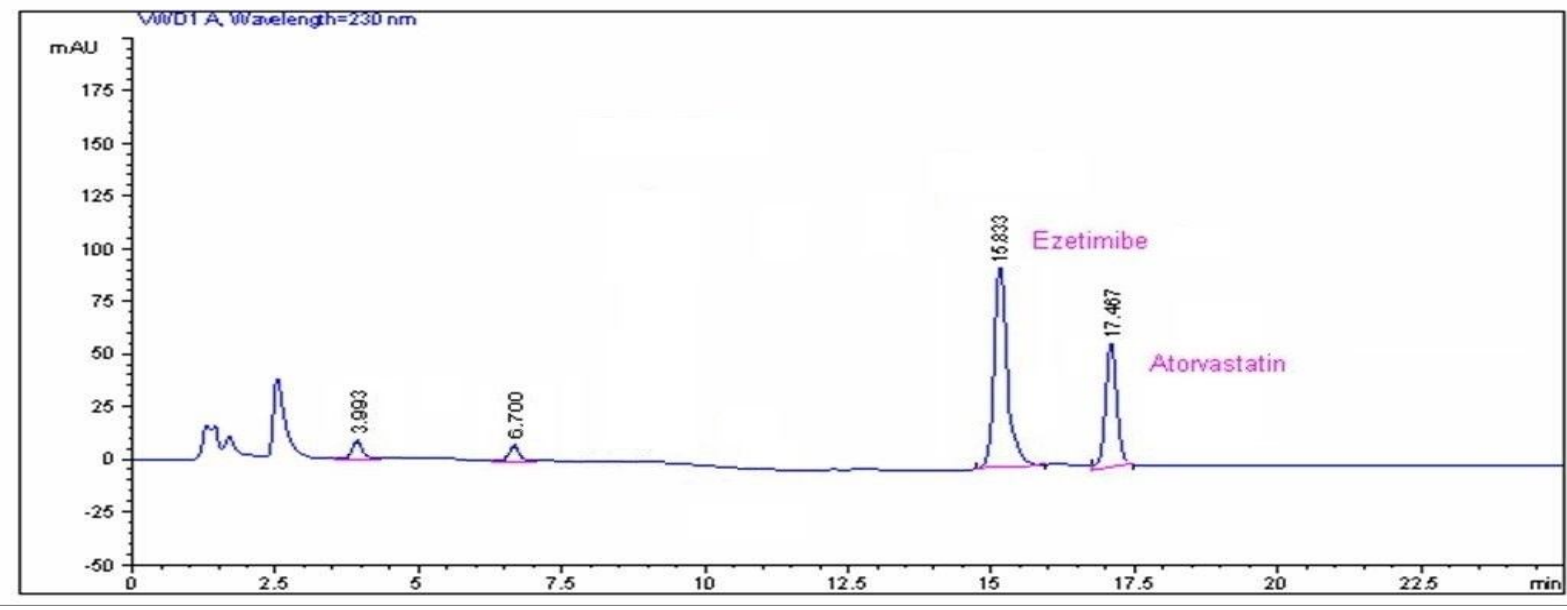

Figure-10: Ezetimibe and Atorvastatin base degradation chromatogram

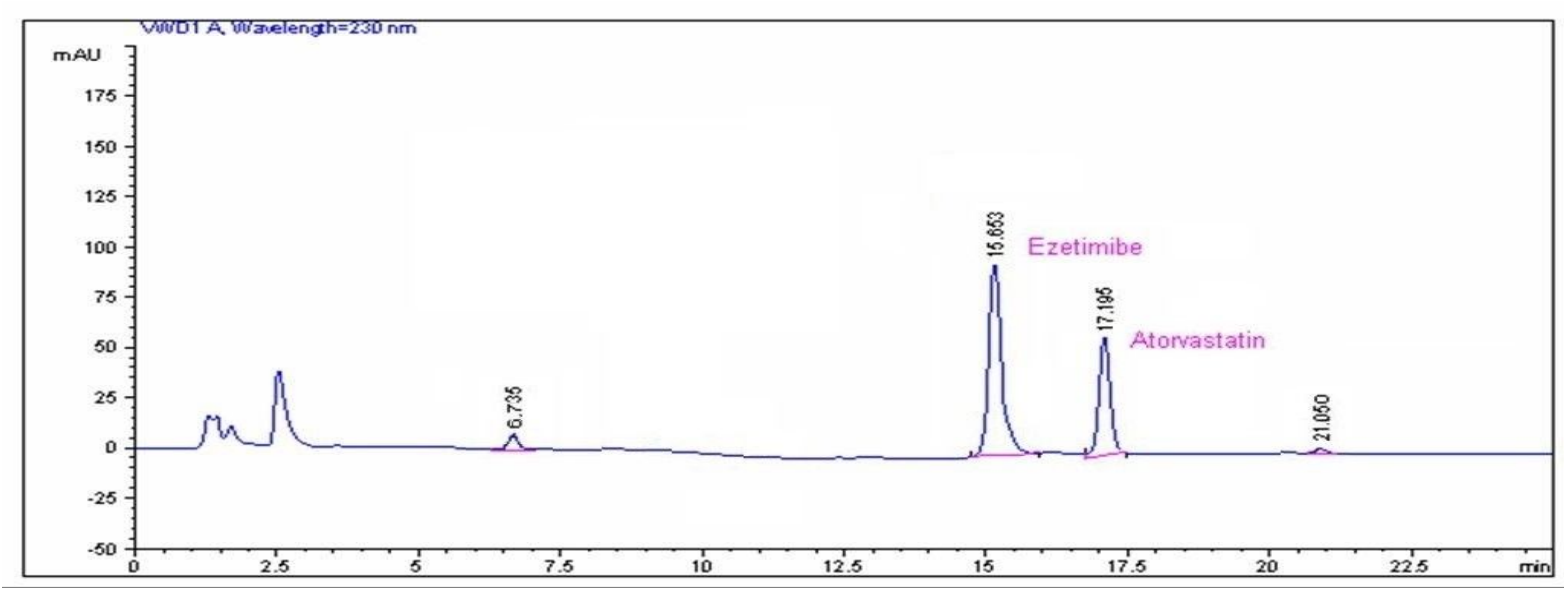

Figure-11: Ezetimibe and Atorvastatin peroxide degradation chromatogram 


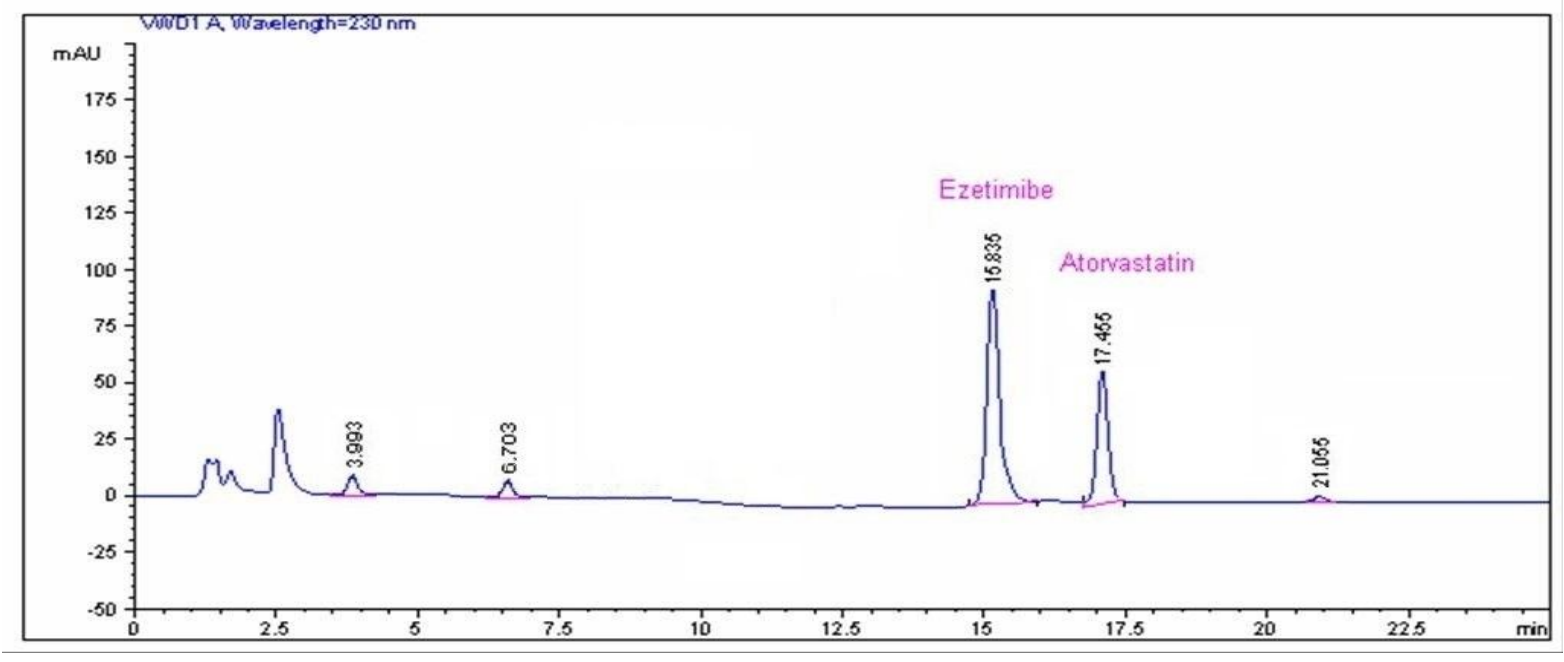

Figure-12: Ezetimibe and Atorvastatin thermal degradation chromatogram

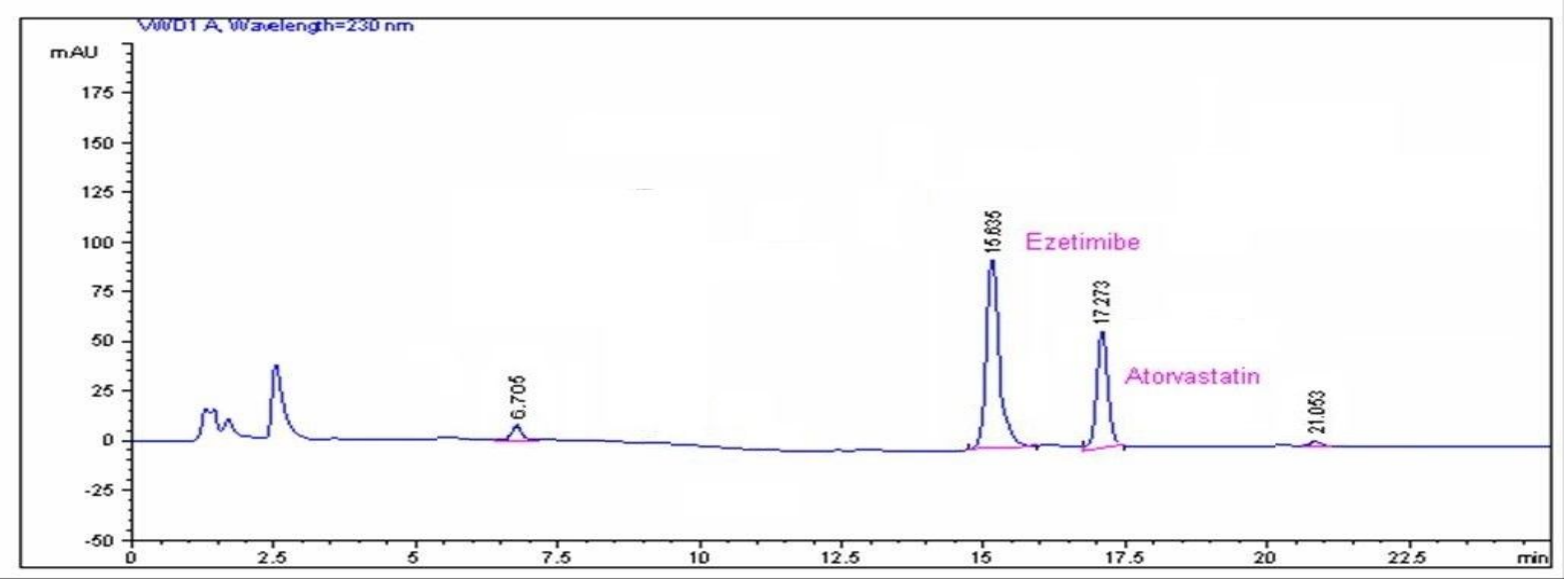

Figure-13: Ezetimibe and Atorvastatin UV degradation chromatogram

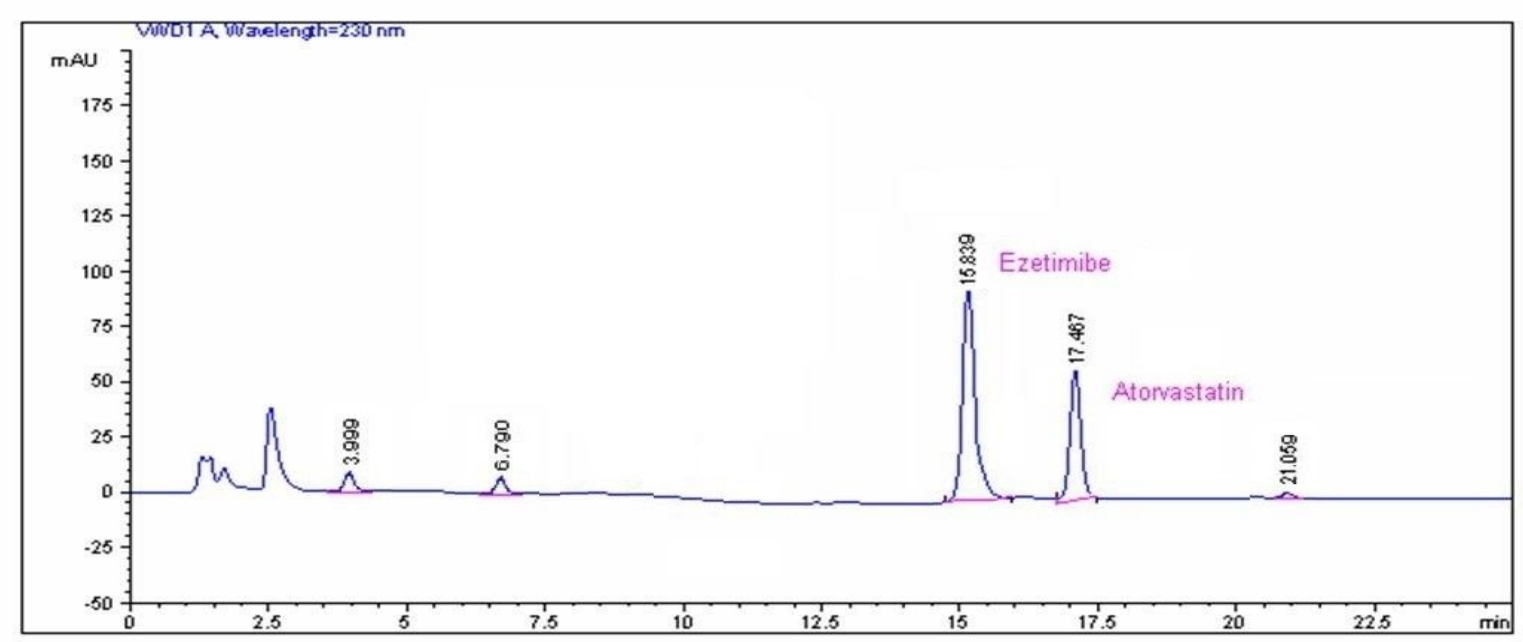

Figure-14: Ezetimibe and Atorvastatin water degradation chromatogram 


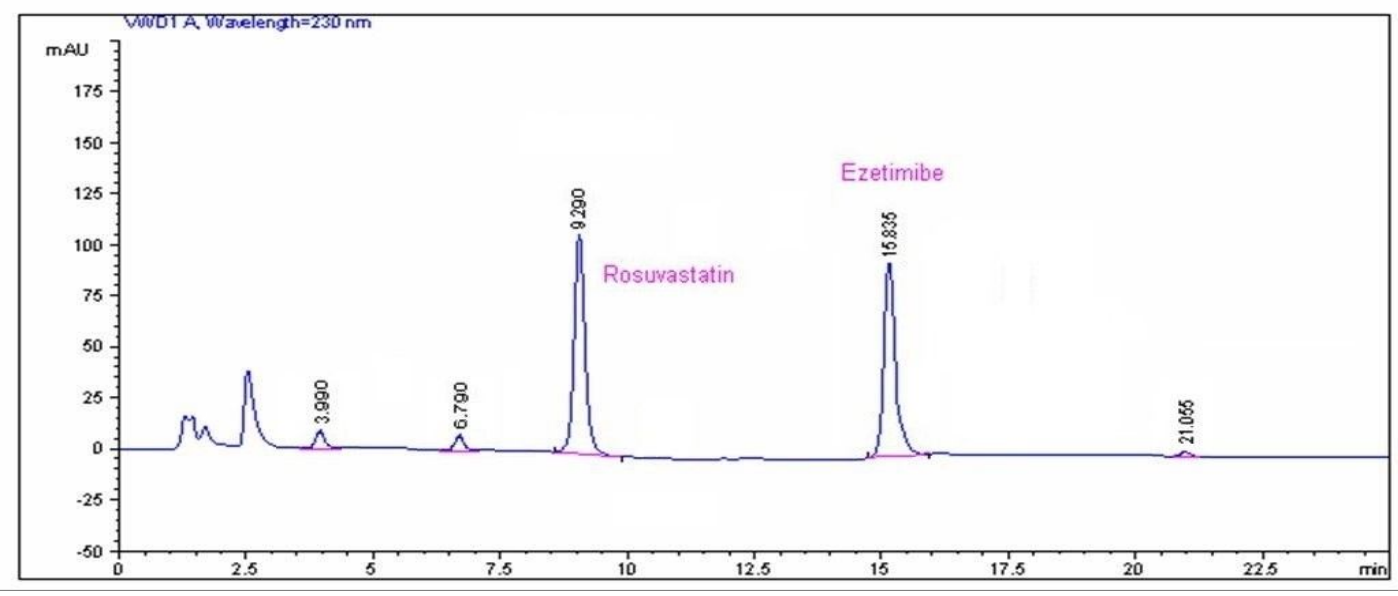

Figure-15: Ezetimibe and Rosuvastatin acid degradation chromatogram

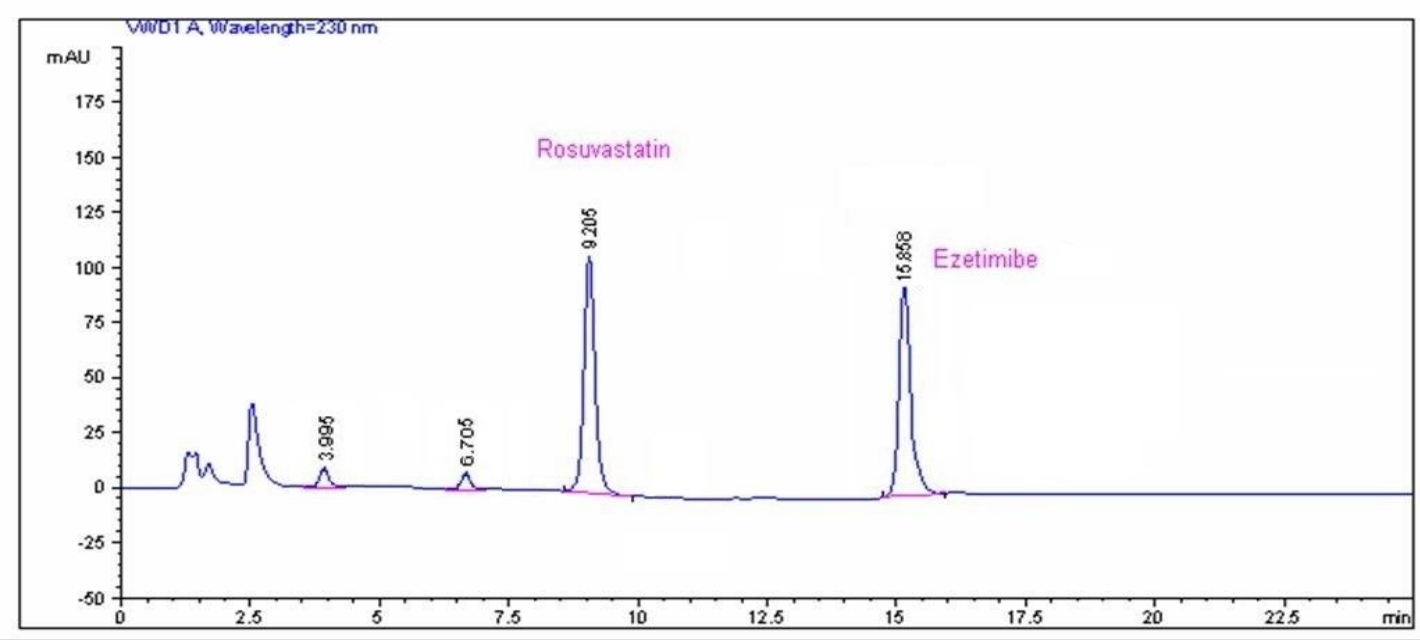

Figure-16: Ezetimibe and Rosuvastatin base degradation chromatogram

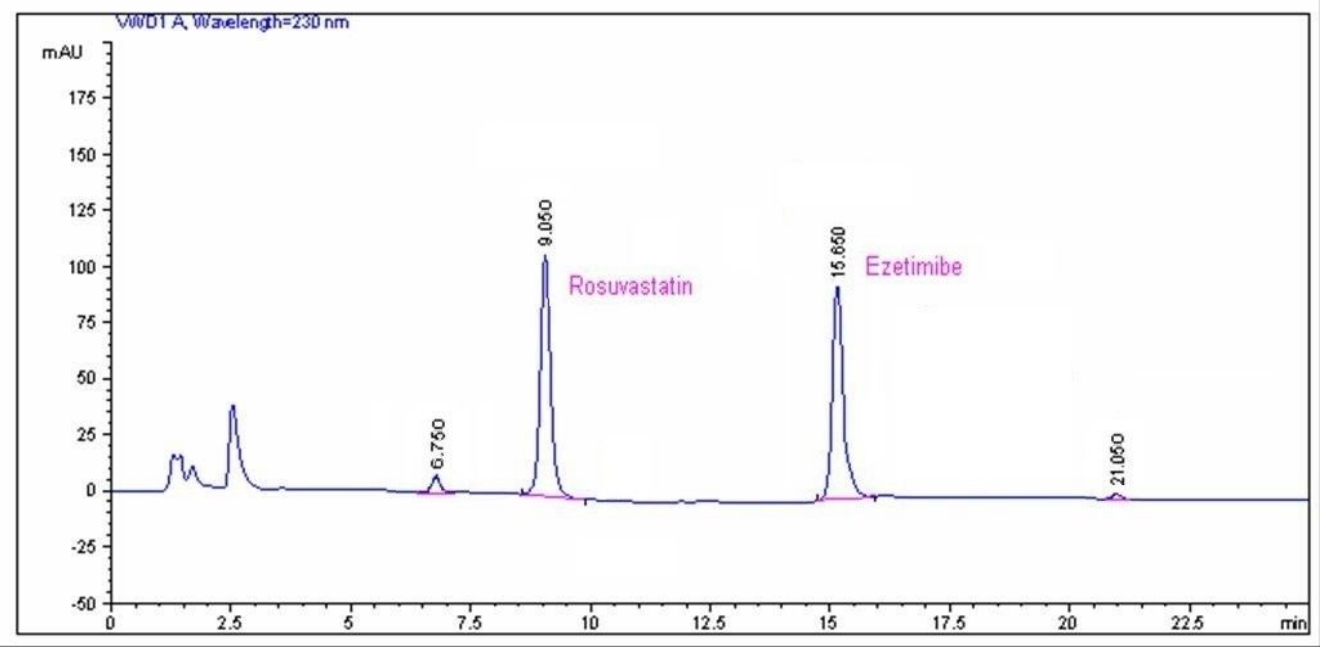

Figure-17: Ezetimibe and Rosuvastatin peroxide degradation chromatogram 


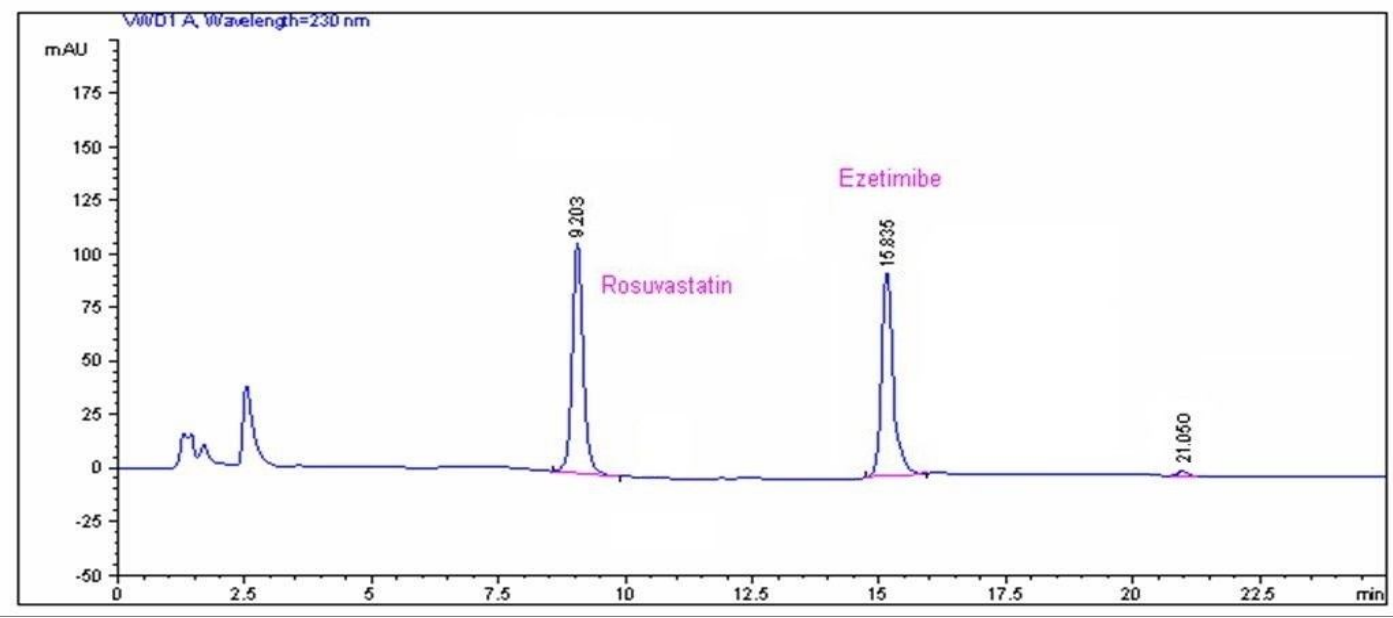

Figure-18: Ezetimibe and Rosuvastatin thermal degradation chromatogram

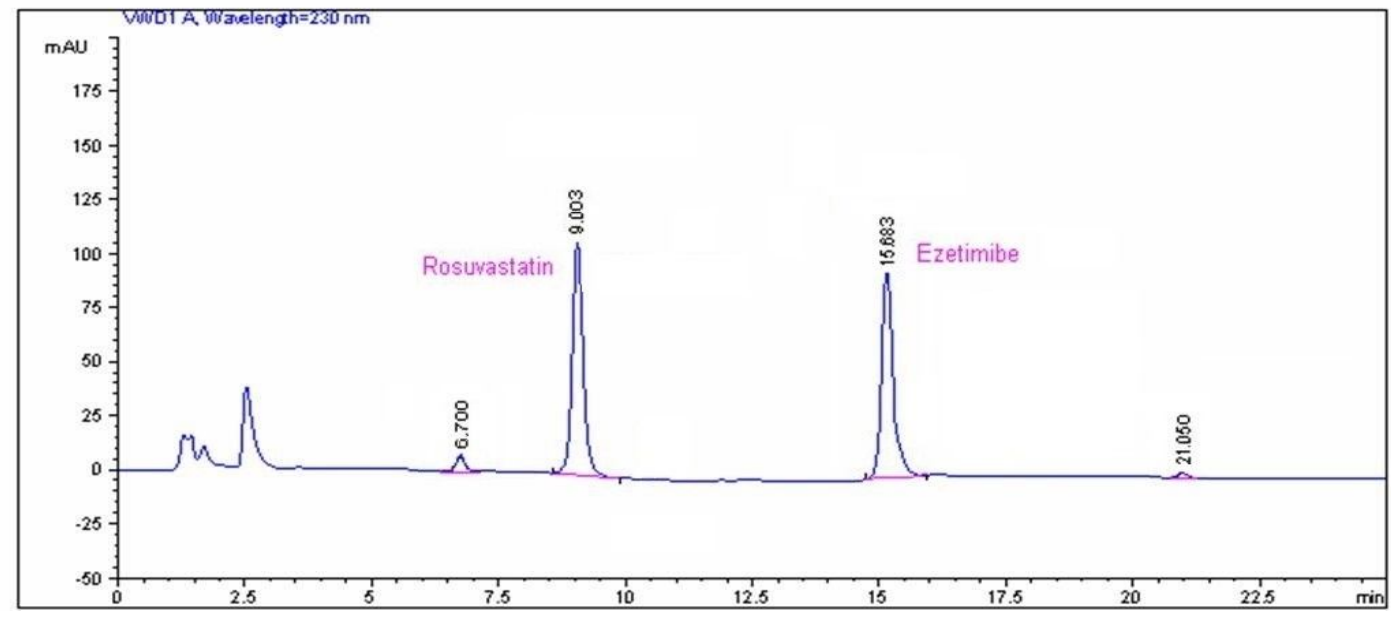

Figure-19: Ezetimibe and Rosuvastatin UV degradation chromatogram

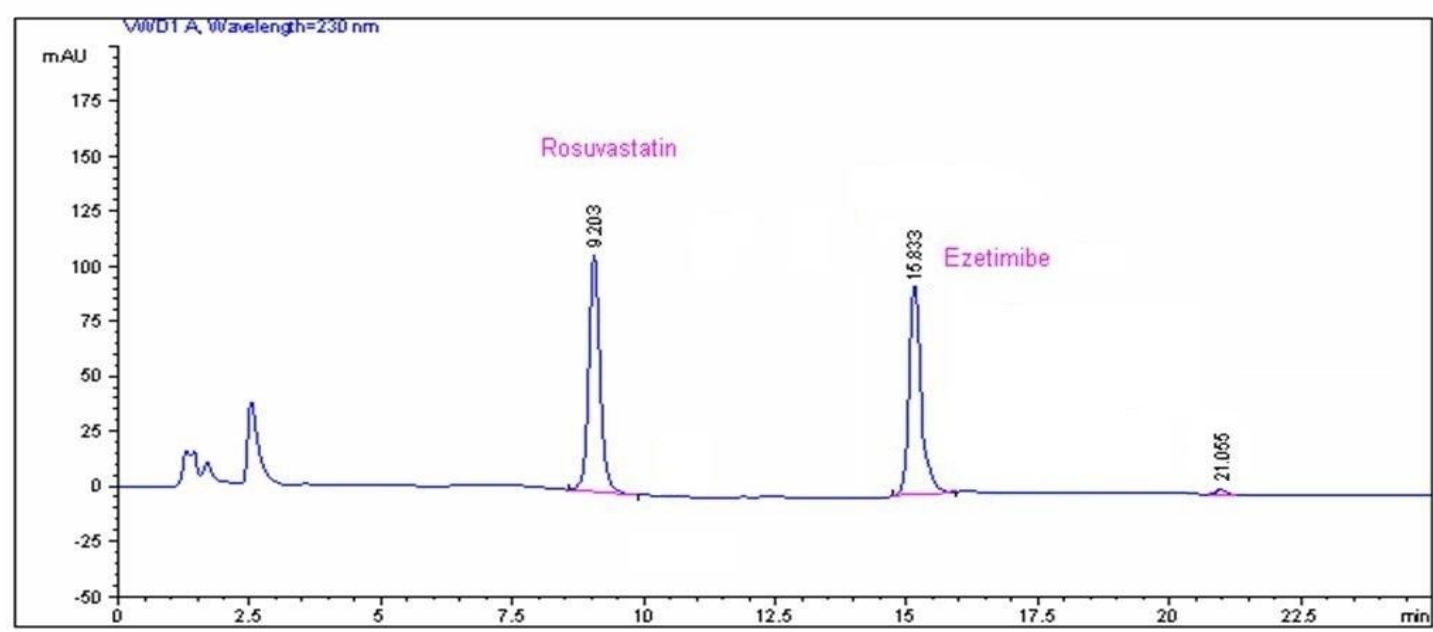

Figure-20: Ezetimibe and Rosuvastatin water degradation chromatogram 


\section{Precision:}

Precision was performed for system precision with 5 replicate standard injections and method precision with 6 replicate sample preparations. Ezetimibe and rosuvastatin tablets were used to prepare the ezetimibe, rosuvastatin sample solution. Ezetimibe and Atorvastatin tablets were used to prepare ezetimibe, Atorvastatin sample solution. Figure-21 to 27 represented the blank, placebo sample, standard solution and test sample chromatograms. Table 3 and 4 summarized the system suitability and precision results.

Table-3: System suitability Results:

\begin{tabular}{|c|c|c|c|}
\hline \multirow{2}{*}{$\begin{array}{l}\text { System } \quad \begin{array}{r}\text { Suitability } \\
\text { parameter }\end{array} \\
\text { replicate injections) }\end{array}$} & \multicolumn{3}{|l|}{ Observations } \\
\hline & Rosuvastatin & Ezetimibe & Atorvastatin \\
\hline Retention time (min) & 9.0 & 15.5 & 17.2 \\
\hline Tailing factor (avg.) & 1.09 & 1.3 & 1.01 \\
\hline$\%$ RSD (5 replicates) & 1.22 & 1.11 & 1.16 \\
\hline
\end{tabular}

Table-4: Method Precision Results:

\begin{tabular}{|c|c|c|c|c|c|c|c|}
\hline \multirow{2}{*}{$\begin{array}{l}\text { Active } \\
\text { Name }\end{array}$} & \multicolumn{6}{|c|}{ Precision sample preparation (\% content) } & \multirow{2}{*}{$\begin{array}{l}\text { \%RS } \\
\text { D }\end{array}$} \\
\hline & 1 & 2 & 3 & 4 & 5 & 6 & \\
\hline Rosuvastatin & 100.16 & 99.86 & 99.68 & 100.58 & 100.61 & 101.25 & 0.57 \\
\hline Ezetimibe & 99.18 & 100.25 & 99.76 & 101.21 & 100.56 & 101.31 & 0.82 \\
\hline Ezetimibe & 101.25 & 101.29 & 100.98 & 100.36 & 100.28 & 100.64 & 0.44 \\
\hline Atorvastatin & 100.29 & 100.28 & 100.25 & 101.29 & 101.21 & 101.52 & 0.59 \\
\hline
\end{tabular}

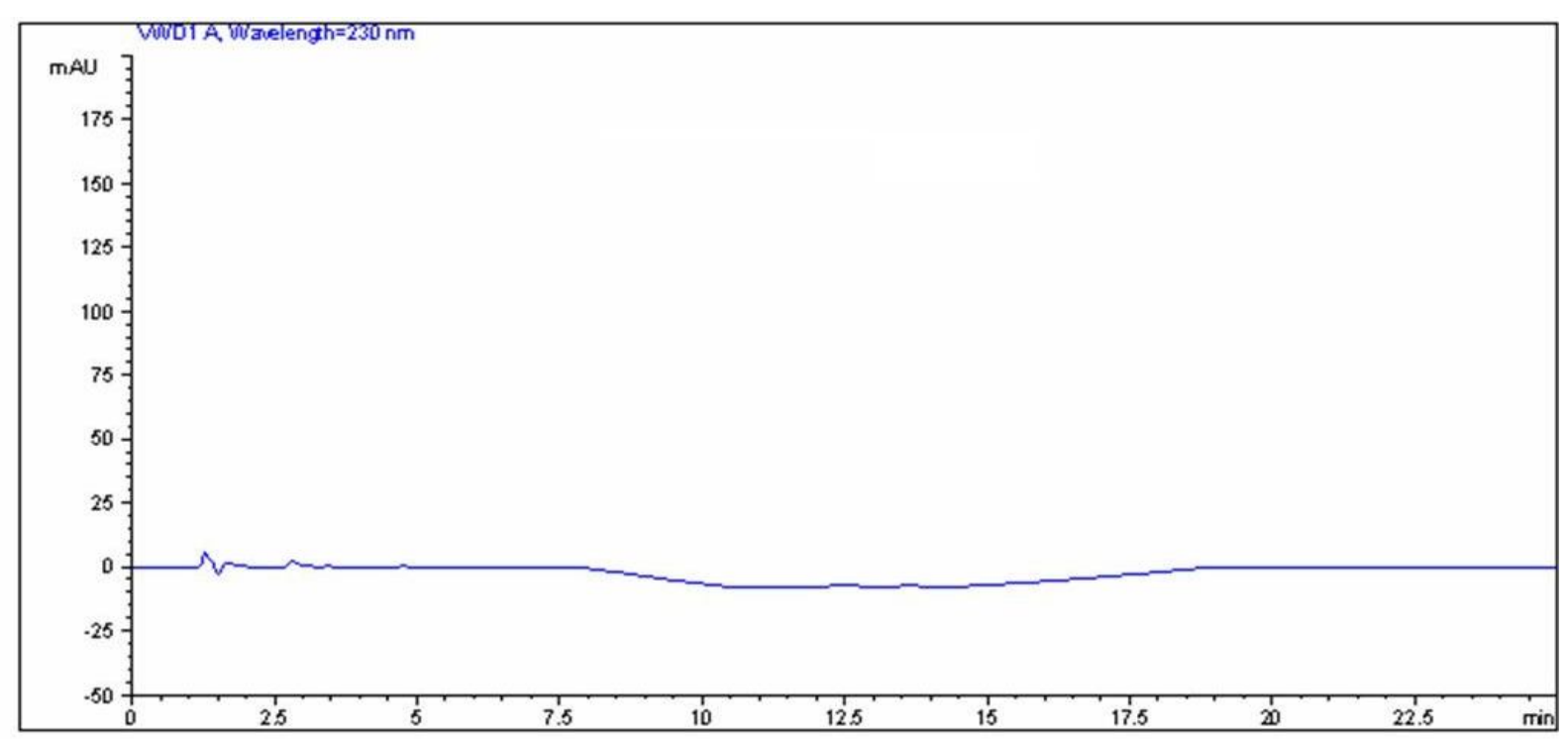

Figure-21: Blank Chromatogram 


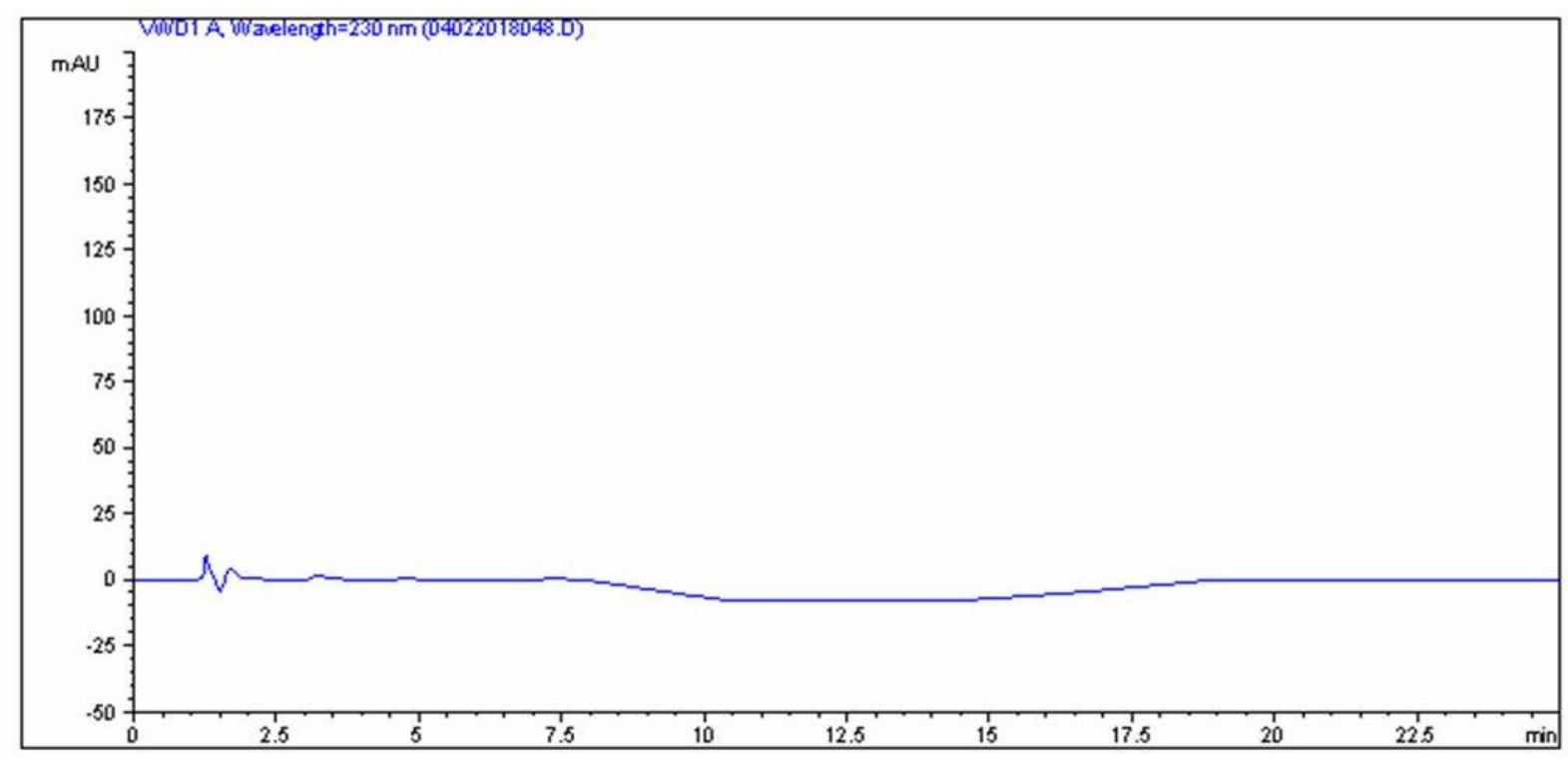

Figure-22: Placebo Chromatogram

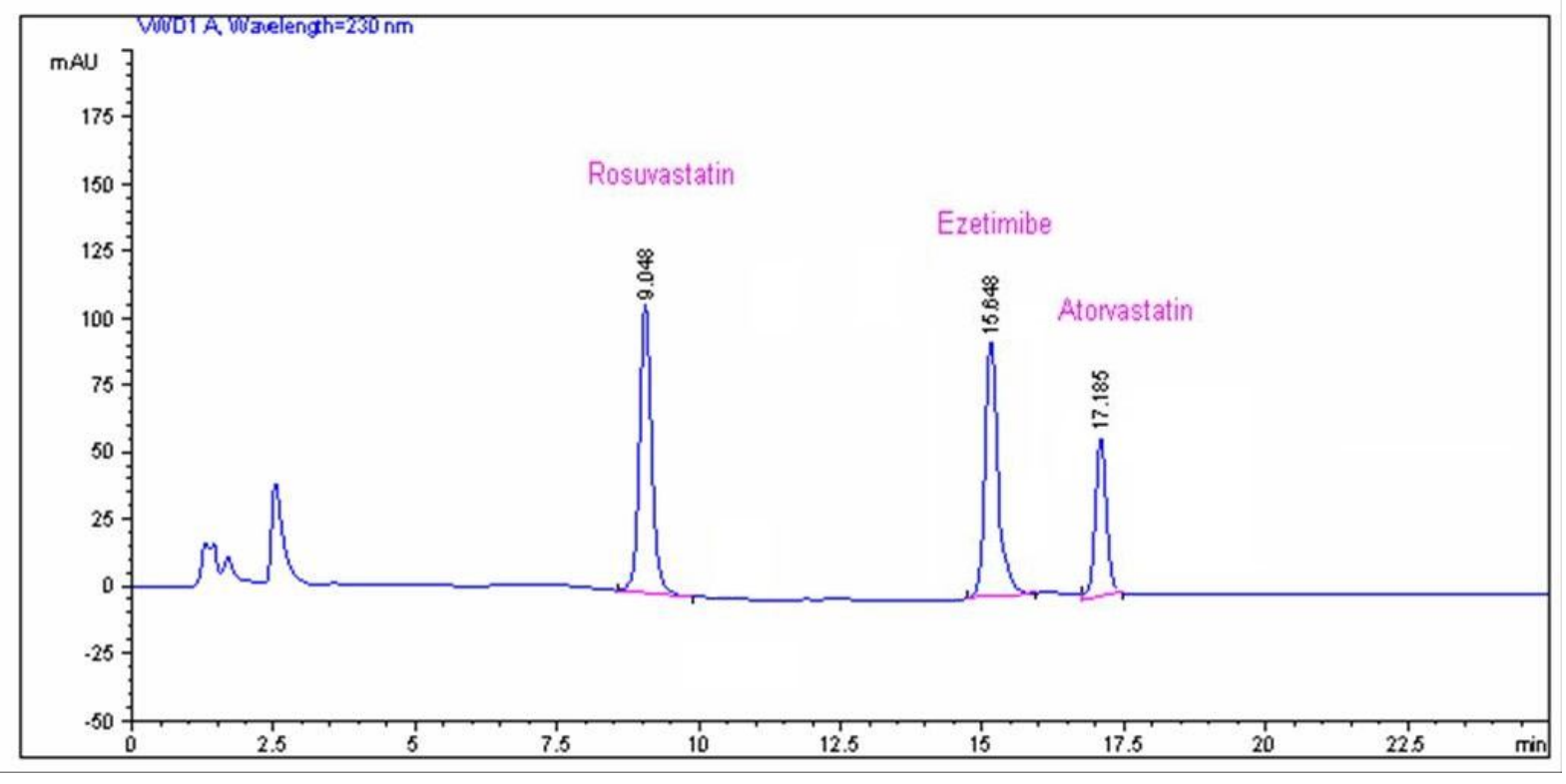

Figure-23: Standard-1 Chromatogram 


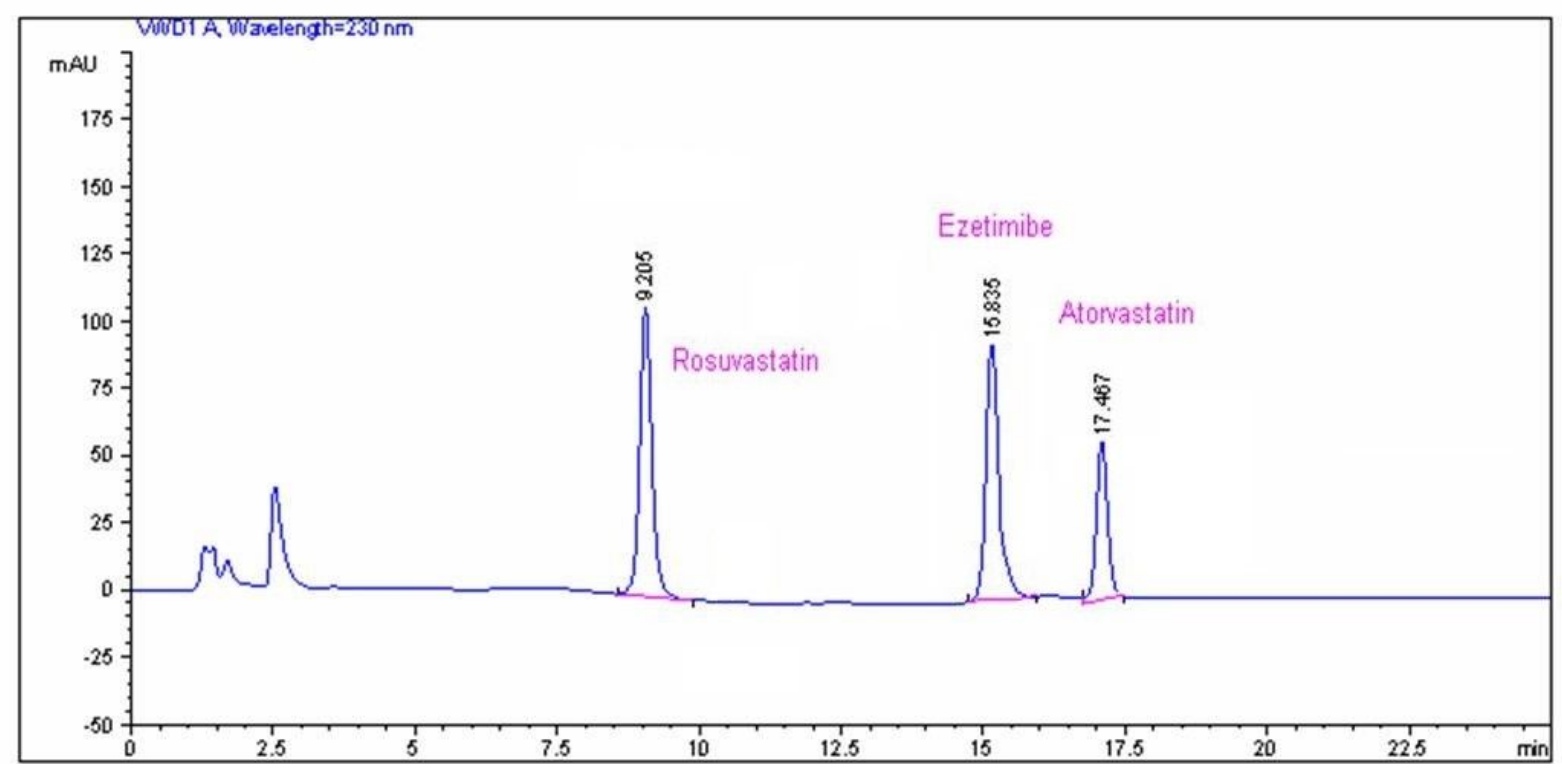

Figure-24: Standard-2 Chromatogram

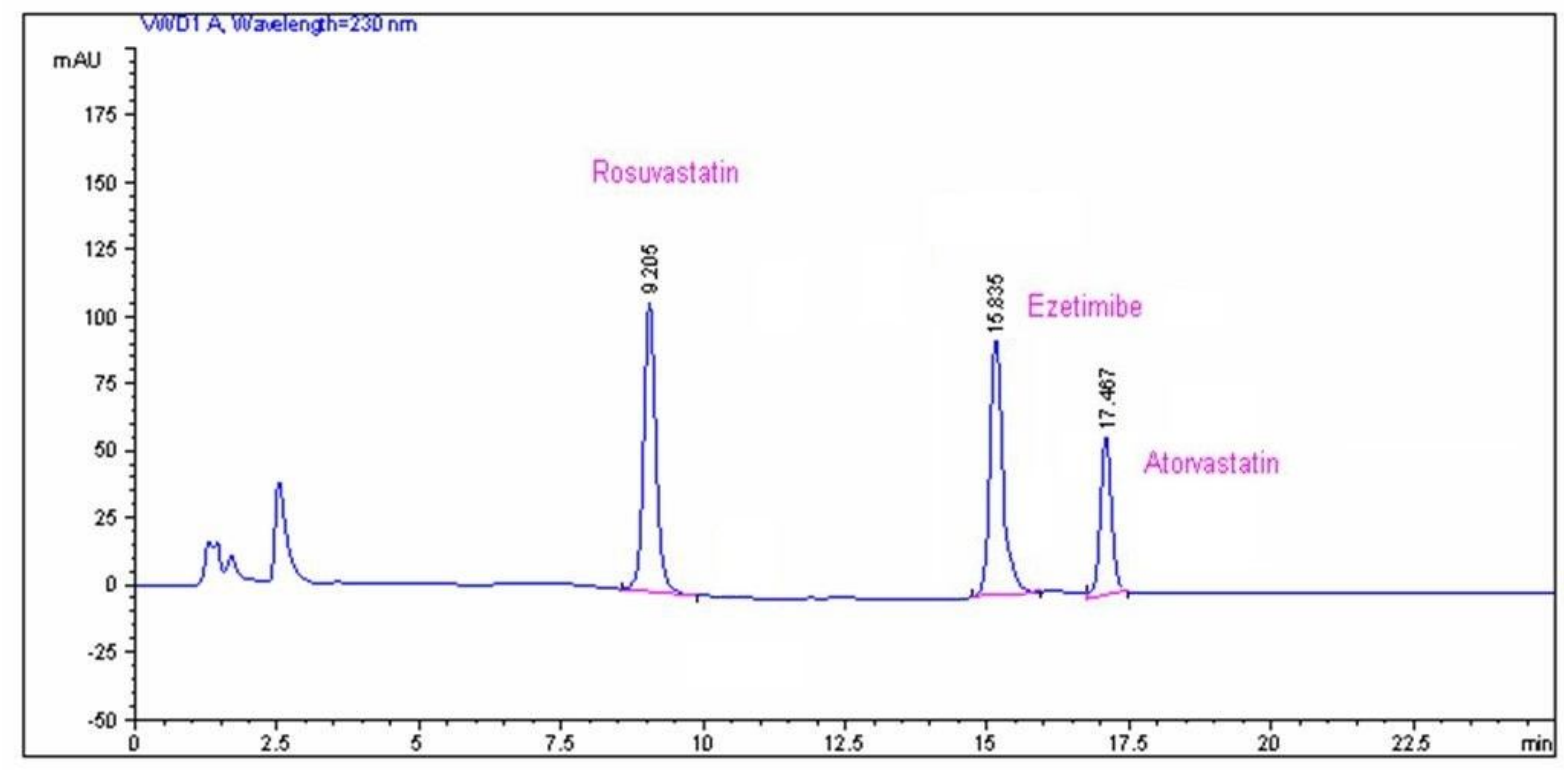

Figure-25: Standard-3 Chromatogram 


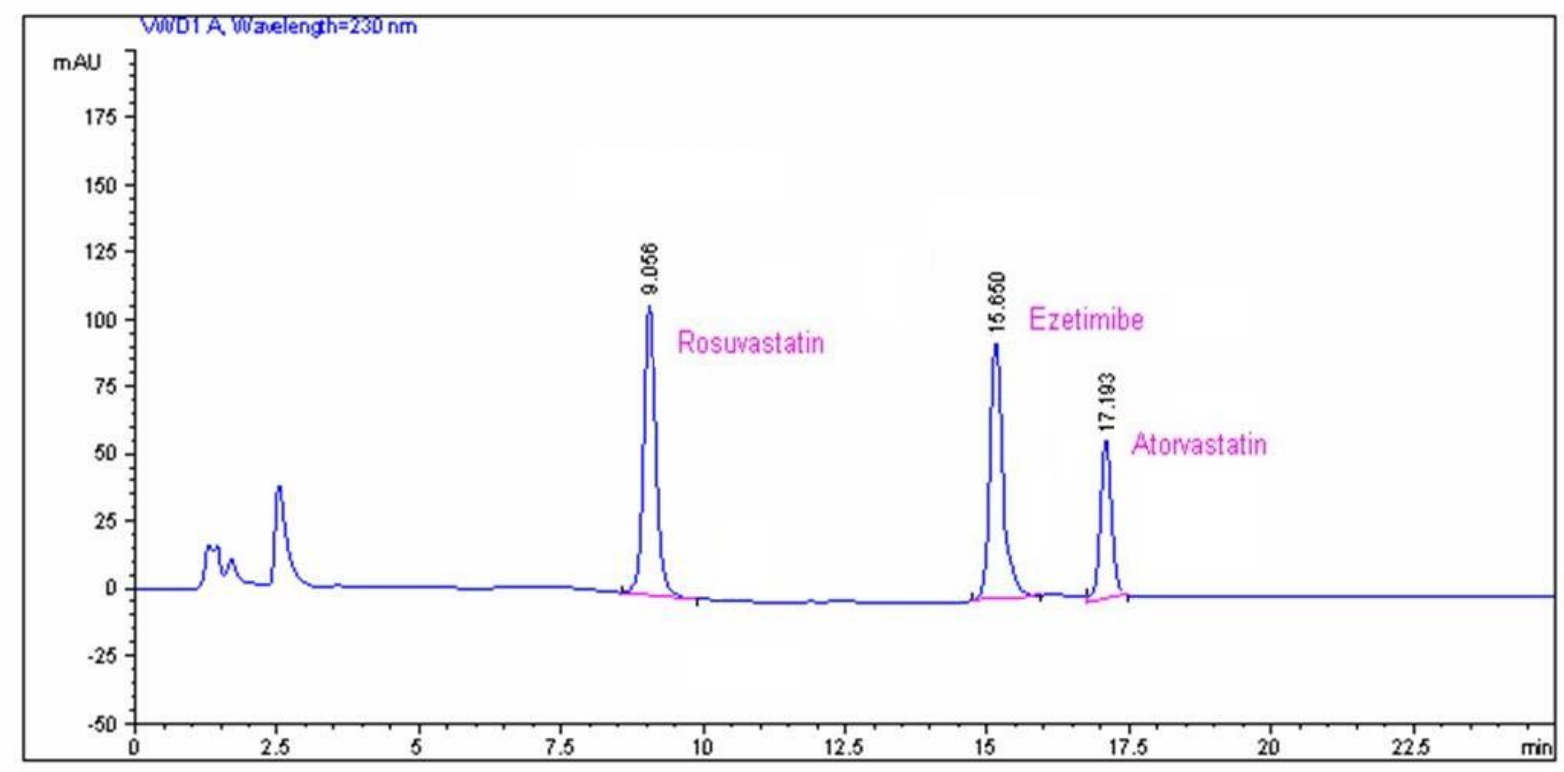

Figure-26: Standard-4 Chromatogram

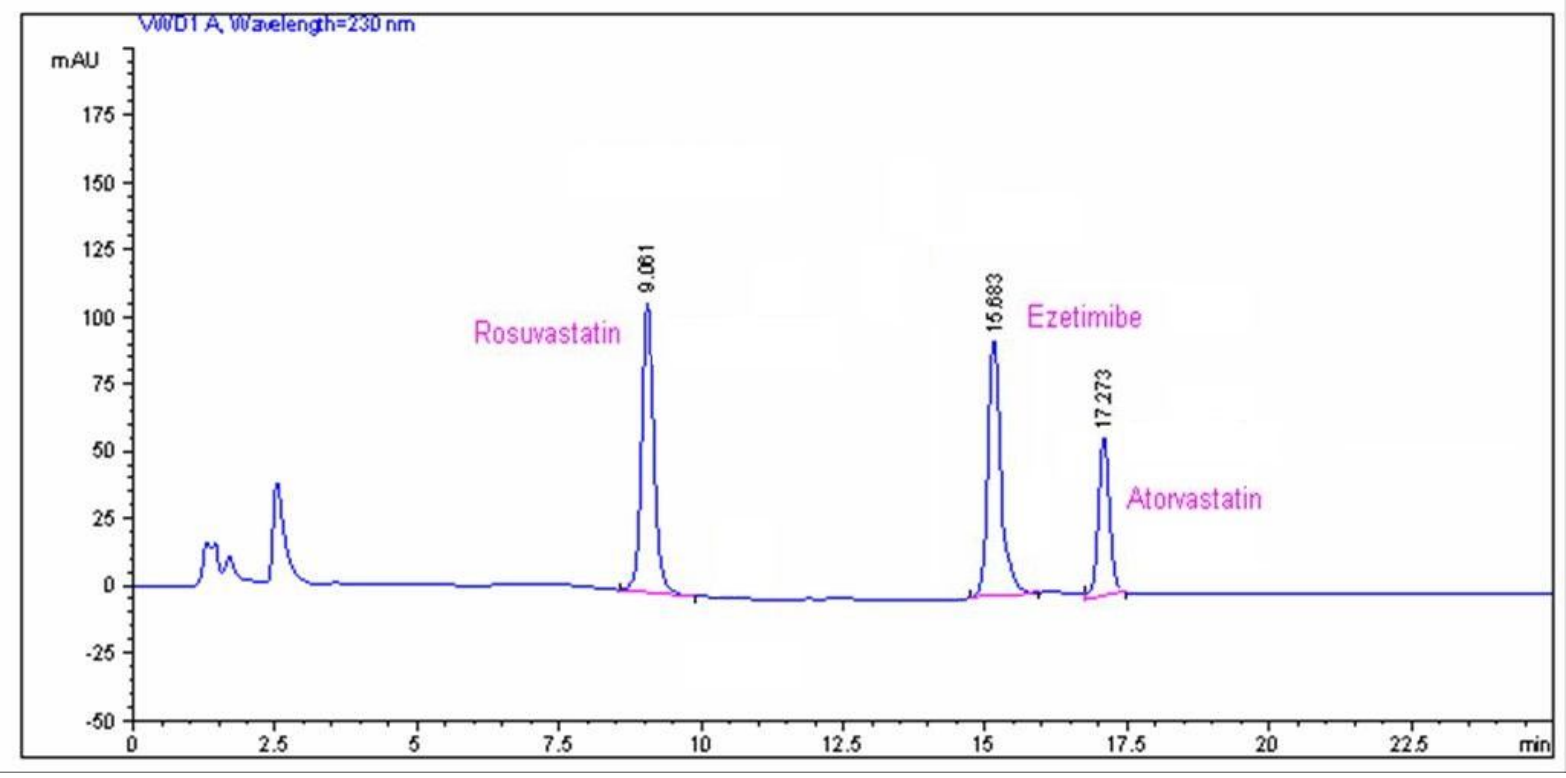

Figure-27: Standard-5 Chromatogram

\section{Linearity:}

Linearity was performed with five different concentration levels. Linearity solutions were prepared $50 \%, 75 \%, 100 \%, 125 \%$ and $150 \%$ of solutions. These samples were prepared as per the finalized method. Linearity chromatograms were repsented in figure-28. Table-5 represented the linearity results. Figure-29 to 31 shown the linearity graph for rosuvastatin, ezetimibe and atorvastatin. 
Table-5: Linearity Results

\begin{tabular}{|l|l|l|l|l|l|l|}
\hline $\begin{array}{l}\text { Linearity } \\
\text { Level }\end{array}$ & \multicolumn{2}{l|}{ Rosuvastatin } & \multicolumn{2}{l|}{ Ezetimibe } & \multicolumn{2}{l|}{ Atorvastatin } \\
\hline $50 \%$ & 28 & 753 & 28 & 1342 & 28 & 2811 \\
\hline $75 \%$ & 42 & 1173 & 42 & 1965 & 42 & 4460 \\
\hline $100 \%$ & 56 & 1600 & 56 & 2653 & 56 & 5950 \\
\hline $125 \%$ & 70 & 1933 & 70 & 3223 & 70 & 7405 \\
\hline $150 \%$ & 84 & 2379 & 84 & 3928 & 84 & 8775 \\
\hline $\begin{array}{l}\text { Correlation } \\
\text { Coefficient }\end{array}$ & 0.9991 & 0.9995 & & 0.9994 & \\
\hline
\end{tabular}

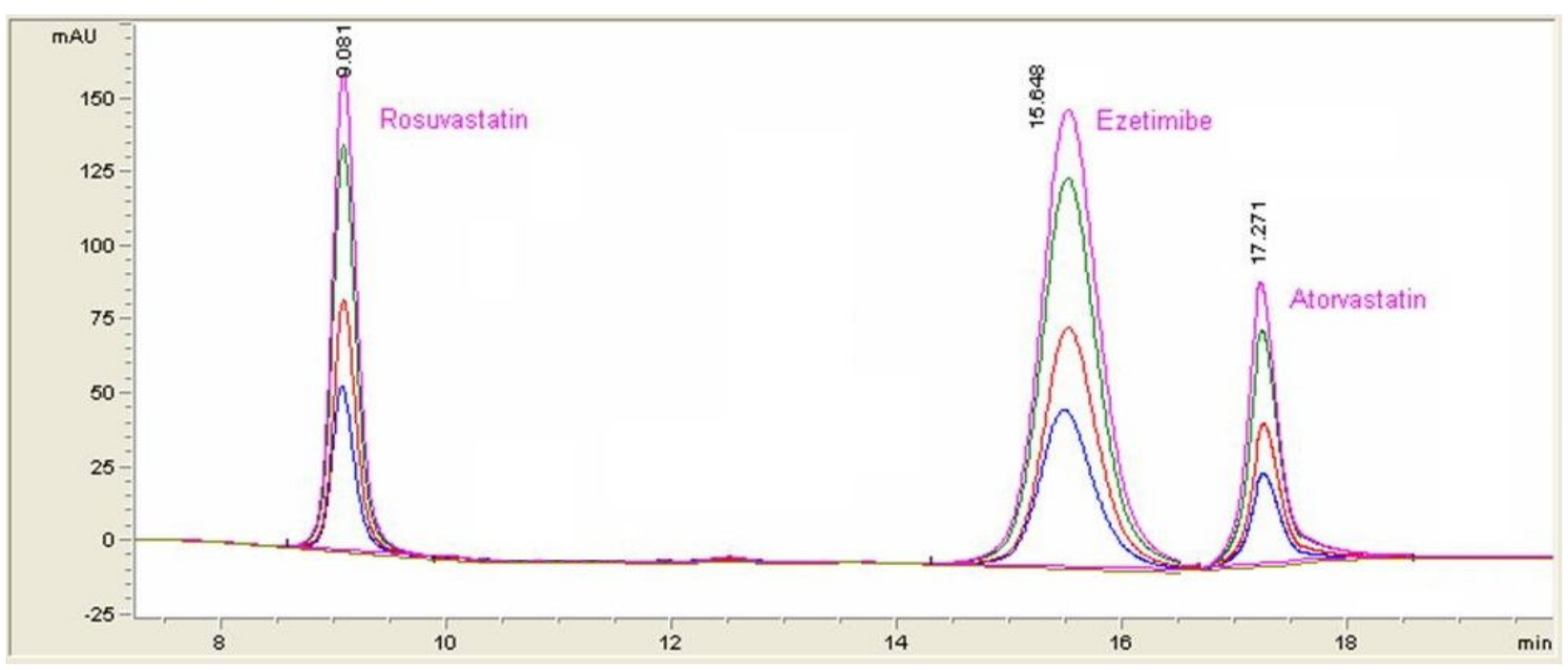

Figure-28: Linearity solutions overlay chromatogram 


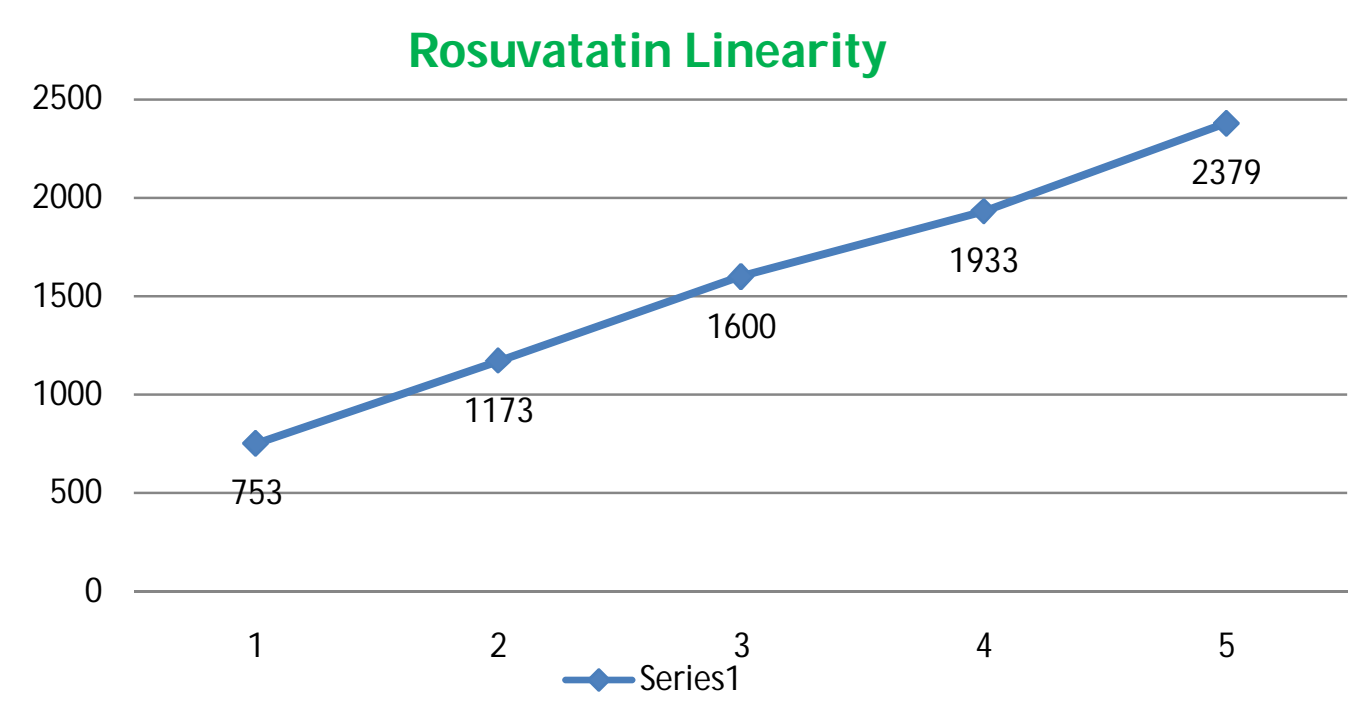

Figure-29: Rosuvastatin Linearity graph

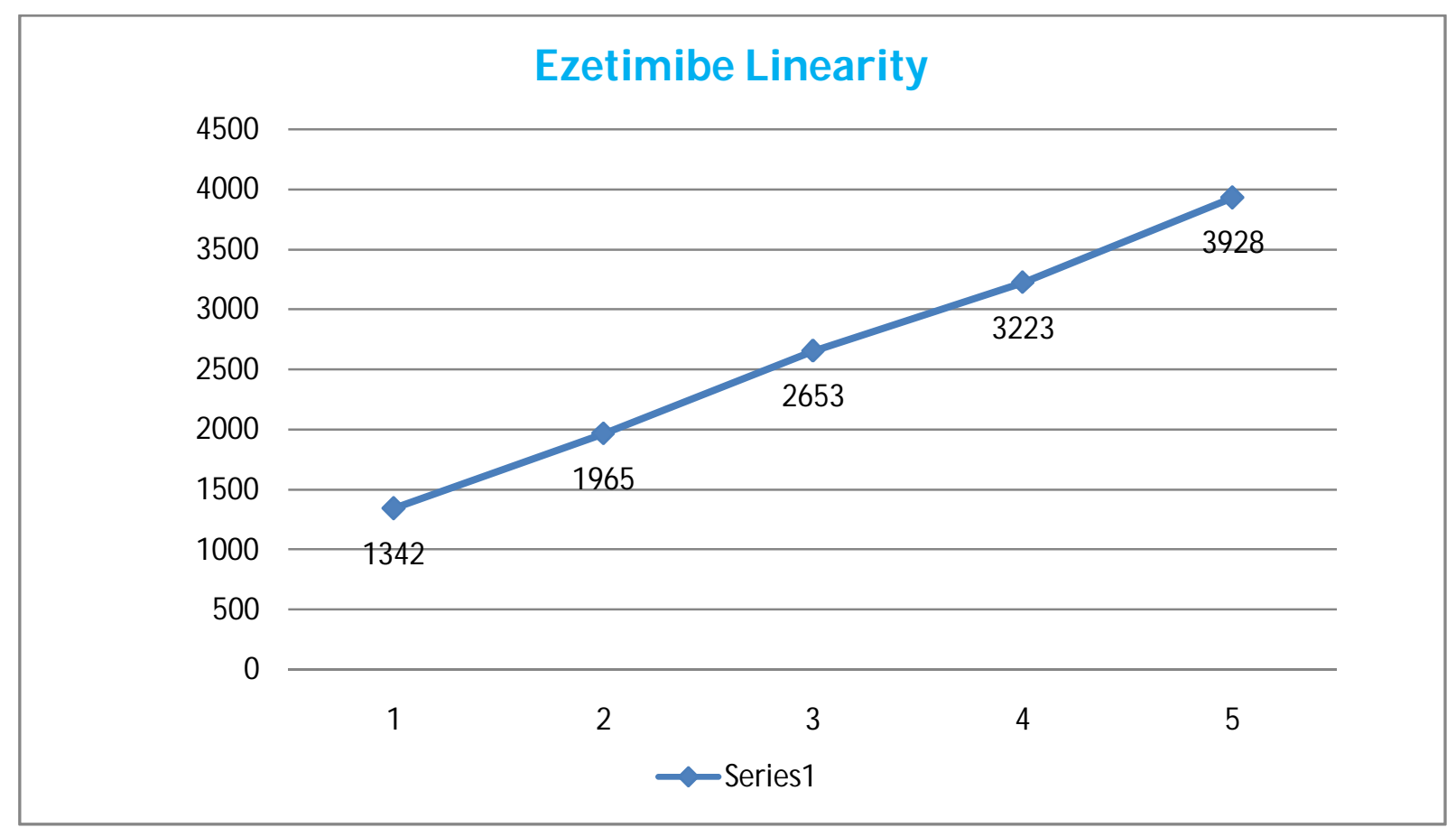

Figure-30: Ezetimibe linearity graph 


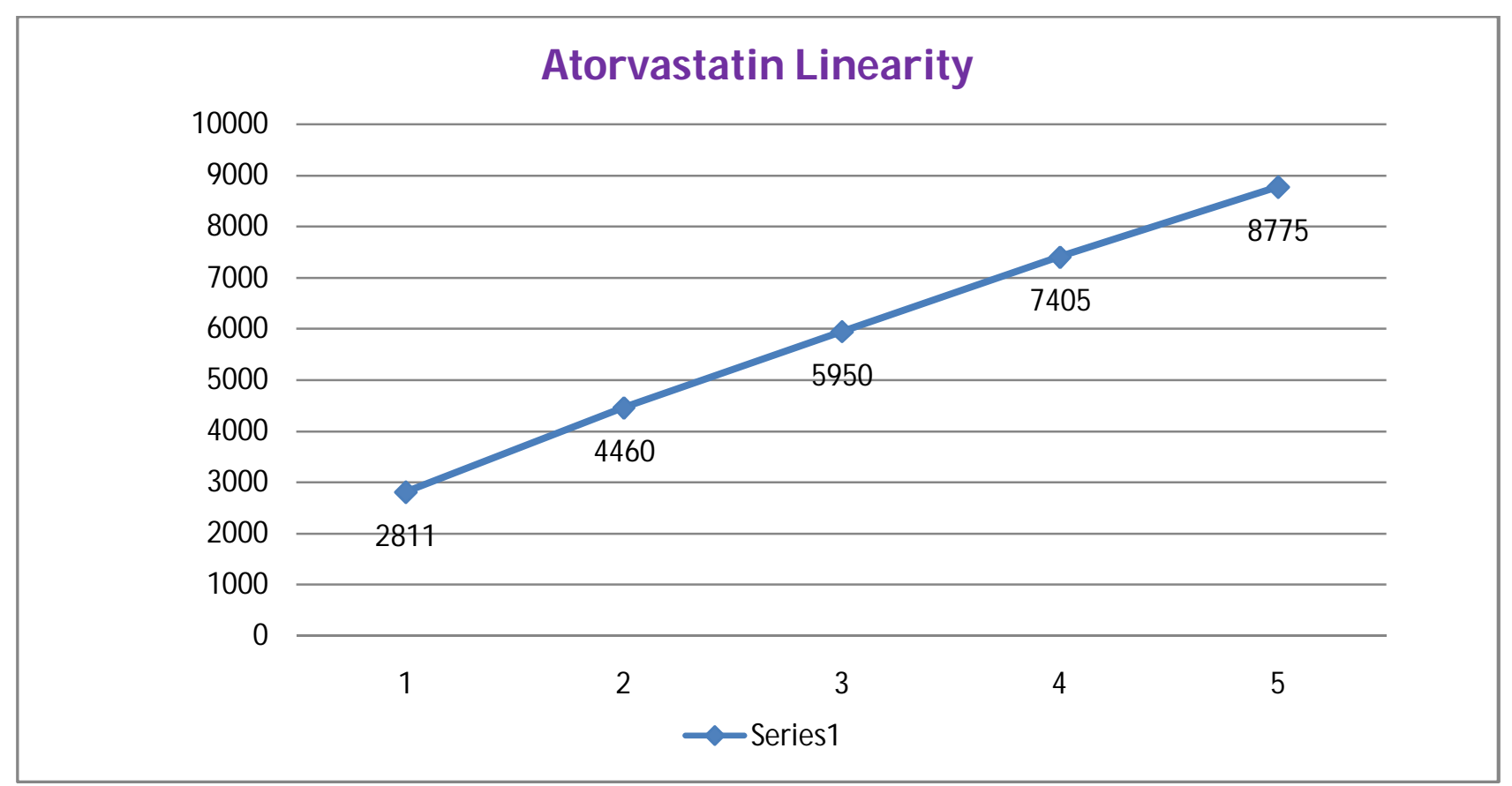

Figure-31: Atorvastatin Linearity Graph

\section{Accuracy:}

Accuracy of the method was determined on three concentration levels by recovery experiments. The recovery studies were carried out by spiked placebo recovery method and the percentage recoveries with standard deviations were calculated. Accuracy results were tabulated in table 6. Method was found to be accurate.

Table-6: Accuracy results

\begin{tabular}{|c|c|c|c|}
\hline \multicolumn{4}{|c|}{ (a) Accuracy results } \\
\hline Level & & Rosuvastatin & \\
\hline \multirow{3}{*}{$50 \%$} & 28.01 & 27.19 & 97.07 \\
\hline & 28.04 & 27.87 & 99.39 \\
\hline & 28.07 & 28.13 & 100.21 \\
\hline \multirow{3}{*}{$\begin{array}{l}100 \\
\%\end{array}$} & 56.15 & 55.87 & 99.50 \\
\hline & 56.17 & 56.25 & 100.14 \\
\hline & 55.89 & 56.21 & 100.57 \\
\hline \multirow{3}{*}{$\begin{array}{l}150 \\
\%\end{array}$} & 84.18 & 84.81 & 100.75 \\
\hline & 83.89 & 86.12 & 102.66 \\
\hline & 84.52 & 84.56 & 100.05 \\
\hline \multicolumn{4}{|c|}{ Ezetimibe } \\
\hline \multirow{3}{*}{$50 \%$} & 27.89 & 27.71 & 99.35 \\
\hline & 28.14 & 28.14 & 100.00 \\
\hline & 28.65 & 28.53 & 99.58 \\
\hline 100 & 56.17 & 56.54 & 100.66 \\
\hline
\end{tabular}




\begin{tabular}{|c|c|c|c|}
\hline \multirow[t]{2}{*}{$\%$} & 56.52 & 56.58 & 100.11 \\
\hline & 56.24 & 56.17 & 99.88 \\
\hline \multirow{3}{*}{$\begin{array}{l}150 \\
\%\end{array}$} & 84.87 & 84.36 & 99.40 \\
\hline & 84.56 & 84.57 & 100.01 \\
\hline & 84.31 & 84.39 & 100.09 \\
\hline \multicolumn{4}{|c|}{ Atorvastatin } \\
\hline \multirow{3}{*}{$50 \%$} & 28.14 & 28.18 & 100.14 \\
\hline & 28.61 & 27.81 & 97.20 \\
\hline & 28.15 & 28.65 & 101.78 \\
\hline \multirow{3}{*}{$\begin{array}{l}100 \\
\%\end{array}$} & 56.54 & 56.18 & 99.36 \\
\hline & 56.27 & 56.80 & 100.94 \\
\hline & 56.19 & 56.94 & 101.33 \\
\hline \multirow{3}{*}{$\begin{array}{l}150 \\
\%\end{array}$} & 84.81 & 84.37 & 99.48 \\
\hline & 84.26 & 84.15 & 99.87 \\
\hline & 84.57 & 84.60 & 100.04 \\
\hline
\end{tabular}

\section{Ruggedness:}

Freshly prepared samples were analysed as part of precision parameter. The same samples were stored at room temperature for three days and analysed at day 1 and day-3. Ruggedness was performed with day-1 sample and day 3 sample. Both time intervals results are complying with the specified limits (not more than $2.0 \%$ of assay). Table-7 presented the ruggedness results.

Table-7: Solution stability of Assay samples

\begin{tabular}{|l|l|l|l|l|}
\hline \multirow{2}{*}{ Duration } & \multicolumn{2}{l|}{ Sample solution-1 } & \multicolumn{2}{l|}{ Sample solution-2 } \\
\cline { 2 - 5 } & Actual & \% variation & Actual & \% variation \\
\hline Rosuvastatin & 101.54 & NA & 100.56 & NA \\
\hline Initial & 100.92 & 0.6 & 100.32 & 0.2 \\
\hline Day-1 & 100.26 & 1.3 & 100.34 & 0.2 \\
\hline Day-3 & 100.68 & NA & 99.98 & NA \\
\hline Ezetimibe & 99.89 & 0.79 & 101.00 & 1.02 \\
\hline Initial & 101.60 & 0.92 & 100.06 & 0.08 \\
\hline Day-1 & \multicolumn{5}{|l|}{} \\
\hline Day-3 & 100.14 & NA & 100.65 & NA \\
\hline Atorvastatin & 99.98 & 0.16 & 100.31 & 0.34 \\
\hline Initial & 101.00 & 0.86 & 99.87 & 0.78 \\
\hline Day-1 & &
\end{tabular}




\section{Robustness:}

Robustness parameter was performed with flow variation, column oven temperature variation and filter validation. Flow rate was checked with $0.8 \mathrm{ml} / \mathrm{min}$ and $1.2 \mathrm{ml} / \mathrm{min}$; column oven temperature evaluated at $45^{\circ} \mathrm{C}$ and $55^{\circ} \mathrm{C}$ and filter validation was performed with centrifuged and PVDF filter paper. Results were listed in table 8 and 9.

Table-8: Robustness results

\begin{tabular}{|c|c|c|c|c|c|c|c|c|}
\hline \multirow{2}{*}{ S.No } & \multirow{2}{*}{\multicolumn{2}{|c|}{ Parameter }} & \multicolumn{2}{|c|}{ Rosuvastatin } & \multicolumn{2}{|c|}{ Ezetimibe } & \multicolumn{2}{|c|}{ Atorvastatin } \\
\hline & & & $\begin{array}{l}\text { Tailing } \\
\text { factor }\end{array}$ & $\begin{array}{l}\text { \%RSD } \\
\text { inj.) }\end{array}$ & $\begin{array}{l}\text { Tailing } \\
\text { factor }\end{array}$ & $\begin{array}{l}\text { \%RSD (5 } \\
\text { inj.) }\end{array}$ & $\begin{array}{l}\text { Tailing } \\
\text { factor }\end{array}$ & $\begin{array}{l}\text { \%RSD (5 } \\
\text { inj.) }\end{array}$ \\
\hline 1 & Flow rate & 0.8 & 1.0 & 0.63 & 1.1 & 0.45 & 1.1 & 0.61 \\
\hline 2 & (mL/min) & 1.2 & 0.9 & 0.59 & 1.0 & 0.16 & 1.0 & 0.54 \\
\hline 3 & Temp. $\left({ }^{\circ} \mathrm{C}\right)$ & 45 & 1.1 & 0.14 & 1.2 & 0.61 & 0.9 & 0.16 \\
\hline 4 & & 55 & 1.0 & 1.0 & 0.9 & 0.56 & 1.1 & 1.13 \\
\hline
\end{tabular}

Table-9: Effect of $0.45 \mu \mathrm{m}$ PVDF filters on standard solution

\begin{tabular}{|c|c|c|c|c|c|c|c|}
\hline \multirow{2}{*}{$\begin{array}{l}\text { S. } \\
\text { No. }\end{array}$} & \multirow{2}{*}{$\begin{array}{l}\text { Standard } \\
\text { solution }\end{array}$} & \multicolumn{2}{|c|}{ Rosuvastatin } & \multicolumn{2}{|l|}{ Ezetimibe } & \multicolumn{2}{|l|}{ Atorvastatin } \\
\hline & & $\begin{array}{l}\text { \% } \\
\operatorname{Assay}(w / w)\end{array}$ & $\begin{array}{l}\% \text { of } \\
\text { difference }\end{array}$ & $\begin{array}{l}\% \\
\operatorname{Assay}(w / w)\end{array}$ & $\begin{array}{l}\% \text { of } \\
\text { difference }\end{array}$ & $\begin{array}{l}\% \\
\operatorname{Assay}(w / w)\end{array}$ & $\begin{array}{l}\% \quad \text { of } \\
\text { difference }\end{array}$ \\
\hline 1 & Centrifuged & 100.90 & NA & 104.16 & NA & 100.77 & NA \\
\hline 1 & $\begin{array}{l}0.45 \quad \mu \mathrm{m} \\
\text { PVDF filter }\end{array}$ & 100.63 & 0.27 & 101.16 & 3.00 & 100.17 & 0.60 \\
\hline
\end{tabular}

\section{Conclusion:}

Simple, high resolution and accurate cost effective RP-HPLC method has been developed for estimation of ezetimibe, Rosuvastatin and Atorvastatin in tablet dosage forms. Optimized method was evaluated with all validation parameters such as precision, accuracy, linearity, specificity, ruggedness and robustness. Method has no interference with placebo and diluent. Six replicate test samples assay value \%RSD values were $2.0 \%$, linearity correlation coefficient value was below 0.999 and accuracy recovery \% RSD was $97 \%$ to $103 \%$. The proposed method is simple, fast, accurate and precise for the simultaneous quantification three ingredients in tablets dosage form. The proposed method can be used for the routine analysis.

\section{References:}

1. H Michael Davidson, MC Thomas Garry, Robert Bettis, Lorenzo Melani, J Leslie Lipka, P Alexandre Le Beaut Ramachandran, Suresh Steven, Sun Enrico Veltri, "Ezetimibe co administered with Atorvastatin in patients with primary hypercholesterolemia", Journal of the American College of Cardiology, 2002, 40, (12), 2125-2134. 
2. Colin Baigent, "The effects of lowering LDL cholesterol with Atorvastatin plus ezetimibe in patients with chronic kidney disease (Study of Heart and Renal Protection): a randomised placebo-controlled trial", The Lancet, 2011, 377 (9784), 2181-2192.

3. J.P. John Kastelein "Atorvastatin with or without Ezetimibe in Familial Hypercholesterolemia", N Engl J Med, 2008, 358:1431-1443.

4. P. Christopher Cannon, "Ezetimibe Added to Statin Therapy after Acute Coronary Syndromes", N Engl J Med, 2015, 372: 2387-2397.

5. R. Terje Pedersen, "Randomised trial of cholesterol lowering in 4444 patients with coronary heart disease: the Scandinavian Atorvastatin Survival Study (4S) Scandinavian Atorvastatin", Survival Study Group, 1994, 344 (8934), 1383-1389.

6. "MRC / BHF Heart Protection Study of cholesterol lowering with Atorvastatin in 20536 high-risk individuals: a randomised placebo controlled trial Heart Protection", Study Collaborative Group, 2002, 360 (9326) 7-22.

7. K Pyörälä, "Cholesterol Lowering With Atorvastatin Improves Prognosis of Diabetic Patients With Coronary Heart Disease: A subgroup analysis of the Scandinavian", Atorvastatin Survival Study (4S) Diabetes Care, 1997, 20(4): 614-620.

8. Yasuko Kureishi "The HMG-CoA reductase inhibitor Atorvastatin activates the protein kinase Akt and promotes angiogenesis in normocholesterolemic animals", Nature Medicine, 2000, 6, 1004-1010.

9. S Swathi, HT Kumar, PK Rao. "Validated RP-HPLC method for simultaneous determination of rosuvastatin calcium and ezetimibe in pharmaceutical dosage form". Int. J. Pharm. And Pharm. sci. 2015, 7(4):209-13.

10. ME Hassouna, HO Salem. "Stability Indicating New RP-HPLC Method For The Determination Of Rosuvastatin Calcium In Pure And Tablets Dosage Forms". International journal of Applied Pharmaceutical and Biological Research. 207, 2(2):11-27.

11. Y Shah, Z Iqbal, L Ahmad, S Nazir, DG Watson, F Khuda, A Khan, MI Khan, A Khan, F Nasir. "Determination of Rosuvastatin and its Metabolite N-Desmethyl Rosuvastatin in Human Plasma by Liquid Chromatography-High Resolution Mass Spectrometry: Method Development, Validation, and Application to Pharmacokinetic Study”. Journal of Liquid Chromatography \& Related Technologies. 2015, 38(8):863-73.

12. VS Janardhanan, $\mathrm{R}$ Manavalan, $\mathrm{K}$ Valliappan. "Chemometric technique for the optimization of chromatographic system: Simultaneous HPLC determination of rosuvastatin, telmisartan, ezetimibe and atorvastatin used in combined cardiovascular therapy". Arabian Journal of Chemistry. 2016, 9:S1378-87.

13. K Wagh, S Sonawane, S Chhajad, S Kshirsagar. "Development of a RP-HPLC method for separation of ezetimibe in presence of atorvastatin Caclium and simvastatin and its application for quantitation of tablet dosage forms". Asian Journal of Pharmaceutical Analysis. 2017, 7(3):169-75.

14. A Jahangiri, K Adibkia, K Asadpour-Zeynali, Y Javadzadeh, H Hamishehkar, M BarzegarJalali. "Application of multivariate calibration methods, in dissolution testing and 
simultaneous determination of atorvastatin and ezetimibe in their combined solid dosage form”. Pharm Sci. 2016, 22:105-11.

15. M Attimarad. "Capillary Electrophoresis Method Development for Simultaneous Determination of Atorvastatin and Ezetimibe from Solid Dosage Form". Journal of Young Pharmacists. 2017, 9(1):120.

16. B Székely-Szentmiklósi, G Hancu, I Székely-Szentmiklósi, B Kovács, H Kelemen. "Simultaneous determination of atorvastatin and ezetimibe from combined pharmaceutical products by micellar electrokinetic capillary chromatography". Brazilian Journal of Pharmaceutical Sciences. 2017, 53(1).

17. O Yalcin. "Development of a Suitable Dissolution Method for the Combined Tablet Formulation of Atorvastatin and Ezetimibe by RP-LC Method". Current Drug Delivery. 2016, 13:1. 